\title{
Contribution of future wide-swath altimetry missions to ocean analysis and forecasting
}

\author{
Antonio Bonaduce ${ }^{1, a}$, Mounir Benkiran ${ }^{1}$, Elisabeth Remy ${ }^{1}$, Pierre Yves Le Traon ${ }^{1,2}$, and Gilles Garric ${ }^{1}$ \\ ${ }^{1}$ Mercator Ocean, Toulouse, France \\ ${ }^{2}$ Ifremer, Plouzané, France \\ anow at: Helmholtz-Zentrum Geesthacht Centre for Materials and Coastal Research, Geesthacht, Germany
}

Correspondence: Antonio Bonaduce (antonio.bonaduce@hzg.de)

Received: 3 May 2018 - Discussion started: 18 June 2018

Revised: 19 October 2018 - Accepted: 26 October 2018 - Published: 16 November 2018

\begin{abstract}
The impact of forthcoming wide-swath altimetry missions on the ocean analysis and forecasting system was investigated by means of OSSEs (observing system simulation experiments). These experiments were performed with a regional data assimilation system, implemented in the Iberian-Biscay-Ireland (IBI) region, at $1 / 12^{\circ}$ resolution using simulated observations derived from a fully eddyresolving free simulation at $1 / 36^{\circ}$ resolution over the same region. The objective of the experiments was to assess the ability of different satellite constellations to constrain the ocean analyses and forecasts, considering both along-track altimeters and future wide-swath missions; consequently, the capability of the data assimilation techniques used in the Mercator Ocean operational system to effectively combine the different kinds of measurements was also investigated. These assessments were carried out as part of a European Space Agency (ESA) study on the potential role of wideswath altimetry in future versions of the European Union Copernicus programme. The impact of future wide-swath altimetry data is evident for investigating the reliability of sea level values in OSSEs. The most significant results were obtained when looking at the sensitivity of the system to wideswath instrumental error: considering a constellation of three nadir and two "accurate" (small instrumental error) wideswath altimeters, the error in ocean analysis was reduced by up to $50 \%$ compared to conventional altimeters. Investigating the impact of the repetitivity of the future measurements, the results showed that two wide-swath missions had a major impact on sea-level forecasting - increasing the accuracy
\end{abstract}

over the entire time window of the 5-day forecasts - compared with a single wide-swath instrument. A spectral analysis underlined that the contributions of wide-swath altimetry data observed in ocean analyses and forecast statistics were mainly due to the more accurate resolution, compared with along-track data, of ocean variability at spatial scales smaller than $100 \mathrm{~km}$. Considering the ocean currents, the results confirmed that the information provided by wide-swath measurements at the surface is propagated down the water column and has a considerable impact $(30 \%)$ on ocean currents (up to a depth of $300 \mathrm{~m}$ ), compared with the present constellation of altimeters. The ocean analysis and forecasting systems used here are those currently used by the Copernicus Marine Environment and Monitoring Service (CMEMS) to provide operational services and ocean reanalysis. The results obtained in the OSSEs considering along-track altimeters were consistent with those derived from real data (observing system experiments, OSEs). OSSEs can also be used to assess the potential of new observing systems, and in this study the results showed that future constellations of altimeters will have a major impact on constraining the CMEMS ocean analysis and forecasting systems and their applications.

\section{Introduction}

Satellite altimetry measurements, based on nadir radar altimeters, have made a fundamental contribution to the un- 
derstanding of ocean circulation (Fu and Chelton, 2001; Le Traon and Morrow, 2001) over the past 2 decades. The continuous improvement of the physics aspects in ocean general circulation models (OGCMs) and of data assimilation schemes (DAS) (Bell et al., 2015) now make it possible to exploit these unique sources of information in global and regional ocean monitoring and forecasting systems (Le Traon et al., 2017b). The focus of the present study is to investigate the impact of wide-swath altimetry on a high-resolution regional ocean analysis and forecasting system. This is carried out as part of a European Space Agency (ESA) study on the potential role of wide-swath altimetry for the further development of the European Union Copernicus programme (space component).

While along-track measurements can observe wavelengths up to between 50 and $70 \mathrm{~km}$ (Dufau et al., 2016), the representation of ocean mesoscale dynamics is strongly limited by the spatial (distance between neighbouring tracks) and temporal (repeat period) sampling of a given altimeter mission. Therefore, it is necessary to use multiple altimeters to constrain the mesoscale circulation (Le Traon et al., 2015) and to provide global maps of the mesoscale variability of the ocean (Le Traon and Dibarboure, 1999; Morrow and Le Traon, 2012). In the literature, studies that focus on the capability of altimeter constellations to resolve ocean dynamics at mesoscale resolution (e.g. Dufau et al., 2016), have concluded that at least three altimeters are required to reconstruct sea-level variations (Pascual et al., 2006; Dibarboure et al., 2011) and that the merging of multiple altimeter missions cannot resolve wavelengths smaller than 150 $200 \mathrm{~km}$ (Ducet et al., 2000; Le Traon, 2013). The shortcomings of conventional altimetry could be addressed by wideswath measurements of sea surface height ( $\mathrm{SSH})$ that are planned for future space missions (e.g. the Surface Water and Ocean Topography mission - SWOT; Fu et al., 2009; Durand et al., 2010); these future measurements will extend the capability of existing nadir altimeters to two-dimensional mapping and sampling of the ocean surface at an unprecedented spatial resolution - to wavelengths as shorts as $20 \mathrm{~km}(\mathrm{Fu}$ and Ferrari, 2008). The forthcoming altimeter missions based on radar interferometry to obtain wide-swath measurements of sea surface elevation (Fu et al., 2009), will make nextgeneration satellite altimetry measurements with a high potential for ocean analysis and forecasting. The NASA/CNES SWOT mission will be the first wide-swath altimetry mission and will be launched in 2021 .

The wide-swath altimetry concept is expected to make an essential contribution to operational oceanography (Bell et al., 2015; Le Traon et al., 2017b). Conversely, the temporal resolution of wide-swath data, considering SWOT-like orbit parameters (repeat cycle of 21 days with a 10-day sub-cycle), may be not suitable for resolving the evolution of mesoscale eddies (Ubelmann et al., 2015). A major challenge will be the combination of data from both wide-swath and conventional along-track altimeters (Pujol et al., 2012) with high resolution OGCMs to enable a dynamical interpolation of wide-swath data and a detailed description and forecast of the ocean state at high resolution. Approaching the challenge of using wide-swath altimetry data to reconstruct oceanic fields, Gaultier et al. (2016) underline the need to test their effective impact on ocean analyses and forecasts by performing observing system simulation experiments (OSSEs). This study is a first attempt at investigating the impact of forthcoming wide-swath altimetry data in an ocean analysis and forecasting system by means of OSSEs.

Observing system experiments (OSEs; e.g. Oke and Schiller, 2007) and OSSEs (e.g. Halliwell et al., 2017) are rigorous methods for demonstrating the impacts of observations (Schiller et al., 2015) on global (Oke et al., 2015a) and regional (Oke et al., 2015b) ocean forecasting systems, as underlined by the GODAE OceanView international Programme (Bell et al., 2015). OSEs analyse the impact of real observations through data denial experiments, where the impact is determined by the increase in analysis and forecast errors due to neglecting a given observing system (Atlas et al., 2015). OSSEs extend this procedure to the assessment of new deployment strategies and sampling characteristics for existing systems, and to the design of new observing systems. Observations are, in the case of OSSE, simulated to mimic the sample and error specification of the future network design and then assimilated.

As described in the literature (e.g. Errico et al., 2013), OSSEs typically use two different OGCMs or two different OGCM configurations. Halliwell et al. (2014) proposed a "fraternal twin" approach, where the same OGCM was used for both the observation simulation and the assimilative model, to assess the impact of Earth observations (EO) in the ocean. This approach was also adopted in this study, using two different configurations of the Nucleus for European Modelling of the Ocean (NEMO; Madec, 2016). The first configuration is used to perform a "natural" run (hereafter NR) to represent the "true" ocean. Synthetic observations are obtained by sampling the NR in order to mimic either an existing or future observing system. Using data assimilation techniques, the synthetic observations are then fed into numerical simulations performed with a second OGCM configuration to obtain a representation of the state of the ocean constrained by the observing system considered (assimilated run). The impact of the simulated observation system is quantified by comparing the assimilated run (AR) with the NR, and the different performances among the OSSEs can then be assessed by the reduction (increase) of ocean analysis and forecast errors due to considering (neglecting) the new observing system designs.

OSSEs are complementary to OSEs and the results for existing observing systems must be consistent with those derived from OSSEs. In particular, the increase (reduction) of the error between the NR and the assimilated run in the OSSEs should have an order of magnitude comparable to that obtained in the OSEs when comparing a realistic ocean 
analysis and forecasting system, which considers real observations, with the real ocean. The calibration of OSSEs with respect to OSEs is important for obtaining robust results from OSSEs (Halliwell et al., 2014, 2017; Kourafalou et al., 2016). In this sense, the choice of the NR, AR, the data assimilation scheme (DAS) and the errors to be considered for the synthetic observations have to be carefully analysed to avoid unrealistic forecast and analysis errors in the OSSEs. In this study we investigated the potential impact of future constellations of satellite altimeters, based on nadir and wide-swath missions, using a regional ocean analysis and forecasting system implemented in the Iberian-Biscay-Ireland (IBI) region at a spatial resolution of $1 / 12^{\circ}$. The system was validated against in situ and satellite observations and continues to provide operational services and ocean reanalysis (Sotillo et al., 2015) within the framework of the Copernicus Marine Environment and Monitoring Service (CMEMS). The system used in this study differs from operational systems in the sense that the same atmospheric forcings are used in both the hindcast and the forecast. First, the system is run freely as a 5-day forecast to compute innovations (observation minus model forecast equivalent). Then, data is assimilated in a 5-day analysis, with the end of the analysis used as initial conditions for the next forecast cycle. Both analyses and forecasting fields are stored to assess the impact of altimetry data in ocean analyses and forecasting skill on the first, third and fifth day of the forecast period.

The main objective of this study was to quantify the impact of assimilating wide-swath altimetry data on errors in ocean analyses and forecasts.

OSSEs are also important tools for testing the capability of a DAS to effectively merge different types of observations with models to produce improved ocean analyses and forecasts. Wide-swath measurement error, due to radar interferometer noise, and its cross-track variability within the swath, will also be a complex issue which must be taken into account (Hénaff et al., 2008) to ensure effective use of the data. In this study, particular attention was paid to the sensitivity of the ocean analysis and forecasting system to instrumental error in wide-swath altimetry measurements. The aim was to test the capability of the Mercator Ocean DAS to use and merge nadir and wide-swath altimeters, which to the best of our knowledge has never been investigated using a regional ocean analysis and forecasting system.

The paper is organized as follows. Section 2 describes the ocean modelling and data assimilation components of OSSEs, as well as the synthetic observations considered in the different experiments. The experimental set-up designed to assess the impact of wide-swath altimetry data is detailed in Sect. 3. The impact of wide-swath data at the surface is investigated in Sect. 4. The contribution of the new observing systems to the representation of ocean variability at different spatial scales is discussed in Sect. 5. Section 6 shows the impact of wide-swath altimetry data on the study of ocean circulation, both at the surface and in the water column. All the results are summarized in Sect. 7 and some conclusions are drawn.

\section{OSSE approach}

ESA is conducting a study to assess the feasibility and potential of wide-swath altimetry for the EU Copernicus programme. The main objective is to provide a much improved operational monitoring of ocean mesoscale variability for the Copernicus Marine Service (e.g. Le Traon et al., 2017a). Different wide-swath altimeter concepts were analysed by Thales Alenia Space (TAS) as part of this ESA study. Compared to the SWOT mission that is focused on sub-mesoscale variability, these European wide-swath altimetry concepts have less stringent noise measurement requirements. Their potential for ocean analysis and forecasting are analysed here by means of OSSEs.

In this section we describe the OSSEs components, represented by the OGCM configurations used to obtain the synthetic observations and to perform data assimilation experiments, the DAS adopted to consider the new observing systems in ocean analysis, and the simulated ocean observations and their errors.

\subsection{OGCM configurations}

In this study, both the NR and the AR rely on the latest version of the NEMO OGCM (NEMO v3.6; Madec, 2016). Following a "fraternal twin" approach (Halliwell et al., 2014), even though the same OGCM type is used, the NR and the AR are configured differently so that the errors (differences between NR and AR) are similar to the those found between state-of-the-art ocean models (e.g. Maraldi et al., 2013; Sotillo et al., 2015) and the true ocean.

The NR is a free-running simulation of the NEMO OGCM, implemented in the IBI region at an eddy-resolving spatial resolution and using an explicit free surface formulation (Madec, 2016; Oddo et al., 2014). The primitive equations are discretized on a horizontal curvilinear grid which is a refined subset at $1 / 36^{\circ}(2-3 \mathrm{~km})$ of the so-called "ORCA" tripolar grid, commonly used in other NEMObased large-scale and global modelling experiments (Barnier et al., 2006). The water column is discretized using 50 unevenly spaced vertical $z$ levels with partial cells to fit the bottom depth shape. A $1 / 36^{\circ}$ horizontal resolution was chosen for the NR in order to resolve the mesoscale in the ocean over almost the entire IBI domain (Hallberg, 2013).

An eddy-resolving OGCM configuration was also used for the AR, but at a coarser spatial resolution to resolve the mesoscale structures with a lower accuracy than the NR. In terms of spatial resolution, the difference between the two configurations is that the AR uses a $1 / 12^{\circ}$ tripolar grid (ORCA12) and 75 vertical levels. A different spatial resolution between the NR and AR configurations was cho- 
Table 1. The nature run (NR) and assimilated run (AR) configurations. The rows show the OGCM configurations used to obtain the nature run (NR) and the assimilated run (AR). The columns show the OGCM used, the horizontal resolution (GRID), the initial (IC) and boundary (BDC) conditions and the atmospheric forcings (ATM) considered in each configuration.

\begin{tabular}{lllll}
\hline & OGCM & GRID & IC \& BDC & ATM \\
\hline NR & NEMO v3.6 & $1 / 36^{\circ}$ & Global analysis (Lellouche et al., 2013); Tides (FES; Carrère al., 2016) & ECMWF analysis \\
AR & NEMO v3.6 & $1 / 12^{\circ}$ & Global reanalysis (GLORYS; Garric et al., 2018); Tides (IBI) & ECMWF ERA-Interim (Dee et al., 2011) \\
\hline
\end{tabular}

sen to determine how assimilating high-resolution data into a coarser OGCM can help increase the accuracy of the representation of the "true" mesoscale dynamics (given by the NR). In order to obtain independent results and quantify the impact of assimilating synthetic satellite altimetry observations from the NR in the AR, the two configurations were initialized differently. Initial conditions in AR were obtained from a 7-year model spin-up (2002-2008) performed as a free run, and forced by atmospheric forcings but without data assimilation.

The AR is forced by $3 \mathrm{~h}, 0.5^{\circ}$ horizontal-resolution atmospheric reanalyses from the European Centre for MediumRange Weather Forecasts (ECMWF ERA-Interim, Dee et al., 2011). Atmospheric pressure and tidal potential (Lyard et al., 2006; Egbert and Erofeeva, 2002) are included in the model forcings. Lateral open boundary and initial condition fields (temperature, salinity, velocities and sea level) are obtained from the Mercator global ocean reanalysis (daily output) at $1 / 4^{\circ}$ (GLORYS; Garric et al., 2018). As the atmospheric pressure forcing is not considered in the global reanalysis, the inverse barometer effects (e.g. Wunsch and Stammer, 1997) are computed from the ECMWF pressure fields and applied along the boundaries. Tidal harmonics were obtained from a 10-year free run simulation, performed using the same OGCM configuration (AR). Conversely, NR is forced by the $3 \mathrm{~h}, 0.25^{\circ}$ horizontal-resolution operational analyses from ECMWF, and Mercator global ocean analysis data are considered as initial and boundary conditions. In this configuration, tidal harmonics were obtained from the most recent version of the FES (Finite Element Solution) tide model (FES2014, Carrère al., 2016). All the differences between the NR and AR configurations are listed in Table 1.

Starting from the same initial conditions, the OSSEs were performed from the 1st of January 2009 over a period of almost 1 year, assimilating synthetic observations from different satellite constellations, in situ temperature, salinity profiles and SST maps.

\subsection{Data assimilation scheme (DAS)}

The impact study designed in this work was performed using an updated version of the data assimilation scheme developed at Mercator Ocean, called SAM2 (Système d'Assimilation Mercator V2), described by Lellouche et al. (2013). In SAM2 the background error covariance matrix is based on a fixed collection of model anomalies. The anomalies are computed from a numerical experiment and at each date they are given by the difference between the free run outputs and their temporal running mean. The aim is to obtain an ensemble of anomalies representative of the error covariances (Oke et al., 2008), which provide an estimate of the error on the ocean state at a given period of the year that is realistic in terms of the climatological statistics.

In this study, we consider a 7-year model run with no data assimilation to obtain anomalies for temperature $(T)$, salinity $(S)$, zonal velocity $(U)$, meridional velocity $(V)$ and sea surface height (SSH). At the date of an analysis the anomalies are considered over a \pm 60 -day time window and from the different years $(\sim 365$ anomalies for each analysis). These anomalies are selected according to the season of the assimilation cycle, in order to get a basis that evolves consistently with the model climatology. In this way the background errors are not propagated by the dynamic model but evolve with time, as errors are based on anomalies that change at each analysis date. In this study, the anomalies were obtained by considering $25 \mathrm{~h}$ averaged fields. The error covariance was localized assuming a zero-covariance beyond a distance defined as twice the local spatial correlation scale, which is about $80 \mathrm{~km}$ in the IBI region. The spatial correlation scales, estimated from IBI regional ocean reanalysis (Sotillo et al., 2015), are also used to select the data around the analysis point.

The model correction (analysis increment) is a linear combination of these anomalies and depends on the innovation (observation minus model forecast equivalent as in Ide et al., 1997) and on the specified observation errors. This correction is applied progressively over the assimilation cycle temporal window using an incremental analysis update (IAU; Bloom et al., 1996; Benkiran and Greiner, 2008) for an enhanced dynamic balance. In this study wide-swath altimetry data were obtained considering a $\sim 20$-day repeat orbit with a 10-day sub-cycle (Gaultier et al., 2016). Here we selected a 5-day assimilation cycle, because it seemed appropriate for the half cycle of wide-swath data, and the ocean analysis was performed in the middle of the assimilation window.

A bias correction based on variational methods (3D-Var) is applied to the model's prognostic equations to correct largescale and slowly evolving errors in $T$ and $S$ diagnosed from the in situ profile innovations. The model equivalents to the SSH observations were computed considering a $25 \mathrm{~h}$ average, to filter the tidal signal. Finally, with respect to the oper- 
(a)

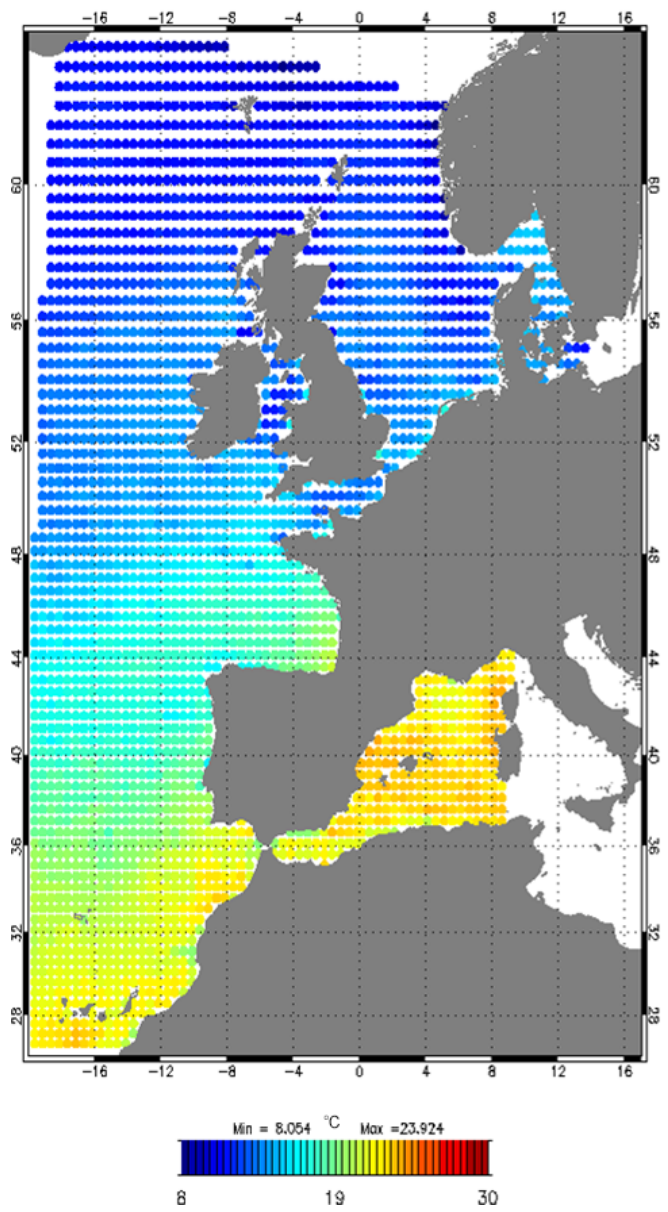

(b) REAIBI12: data number - temperature

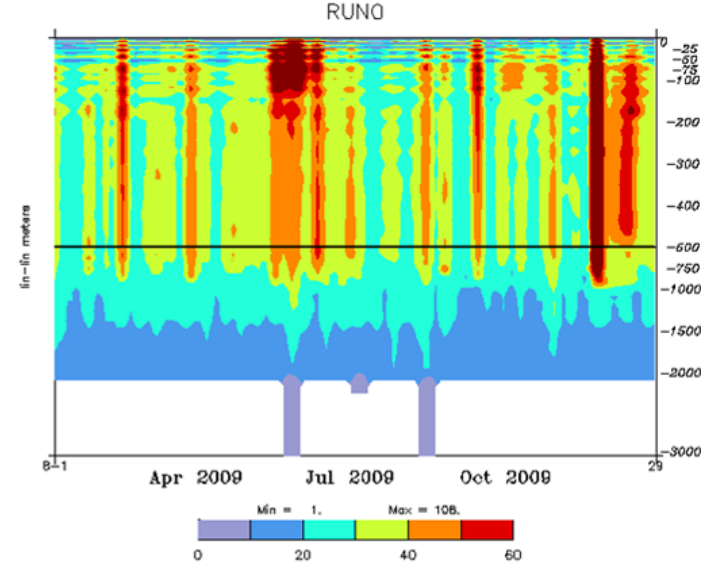

(c) REAIBI12: data number-salinity

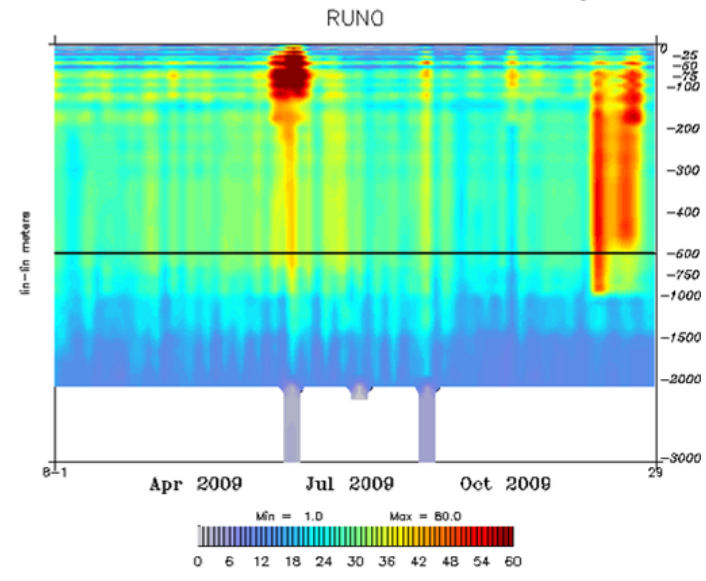

Figure 1. Temperature and salinity simulated data. (a) Sea surface temperature from the NR (15 June 2009). Number of temperature (b) and salinity (c) data during the year 2009 (corresponding to the CORA3.2 database in situ data positions).

ational systems (Lellouche et al., 2013), we assimilated the full SSH signal instead of the sea level anomaly (SLA), as in Verrier et al. (2017). As proposed by Errico et al. (2013), the background error and observation error statistics are specified as in the operational system for SST and in situ observations, and the same quality control and data selection procedures are used considering either simulated or real data in order to obtain results in the OSSEs that can match those from a real ocean analysis. A specific OSSE, not shown here, was performed for calibration purpose mimicking the present altimetric observing systems with a $3 \mathrm{~cm}$ observation error prescribed on along-track observations, instead of $1 \mathrm{~cm}$, as chosen for OSSE1 (Sect. 3) presented in this paper. In the open ocean, the innovation statistics for the along-track observations in this OSSE and in the IBI system assimilating real observations have a similar amplitude and patterns.

\subsection{Simulation of observations}

\subsubsection{Sea surface temperature (SST) and temperature and salinity profiles}

To accurately assess the impact of satellite altimetry data on ocean analyses and forecasts, the same synthetic observations of SST, $T$ and $S$ profiles were considered in all of the experiments. An SST map representing a daily average is assimilated during each 5-day assimilation cycle. Figure 2 shows an example of a synthetic SST field to be assimilated for 15 June 2009. Temperature and salinity profiles are extracted at the same points and the same dates as the real in situ profiles found in the CORA3.2 database from CORIOLIS data centre (Cabanes et al., 2013). Figure $1 \mathrm{~b}$ and $\mathrm{c}$ show the number of $T$ and $S$ profiles available during 2009 over the IBI region. 
(a) Ssh from $\mathrm{J} 2, \mathrm{Cs}, \mathrm{S3a}(03-08 / 01 / 2009)$

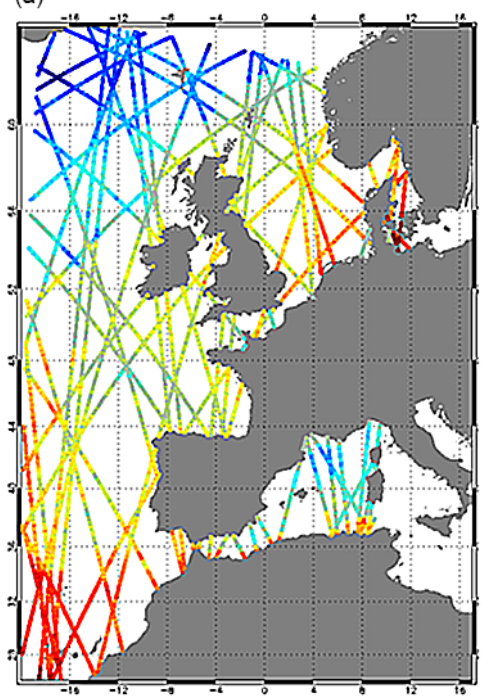

(b)

(b)

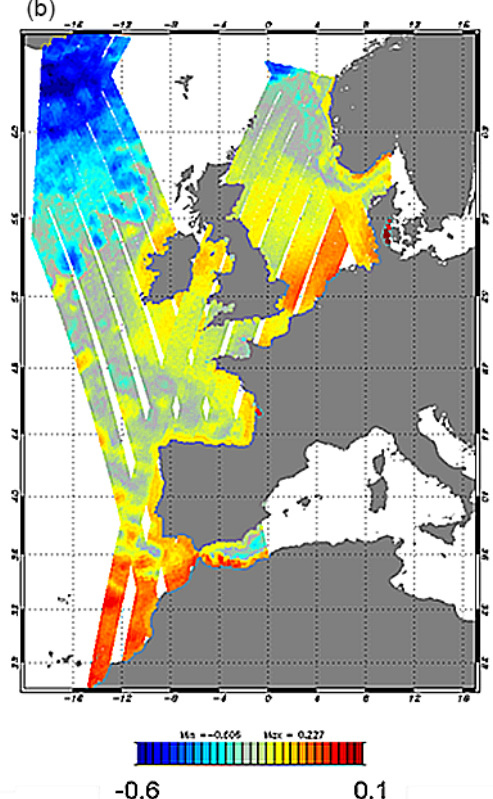

(c)

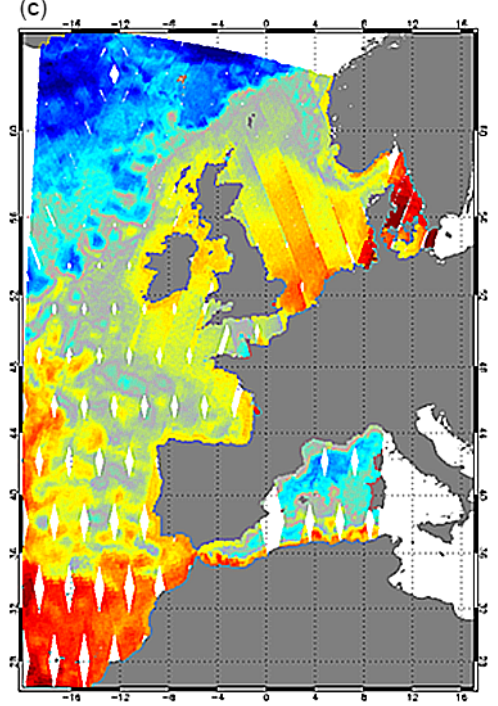

(d)

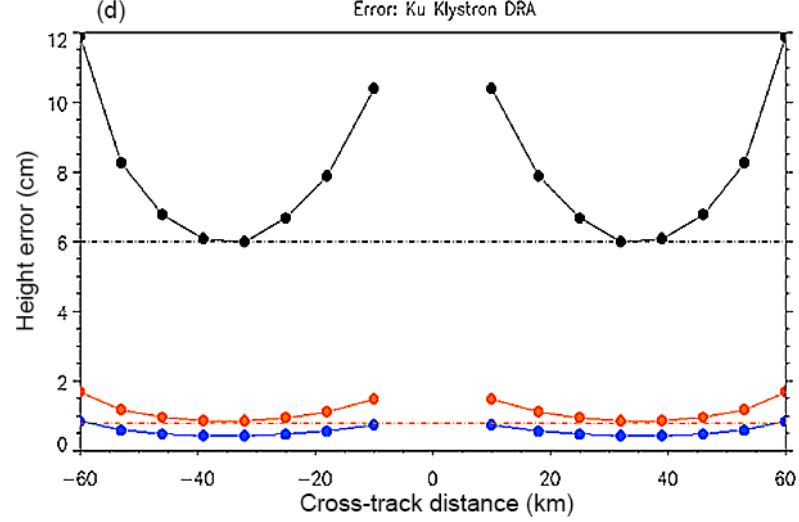

(e)

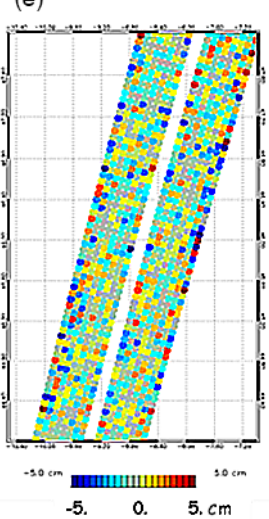

(f) Ssh model

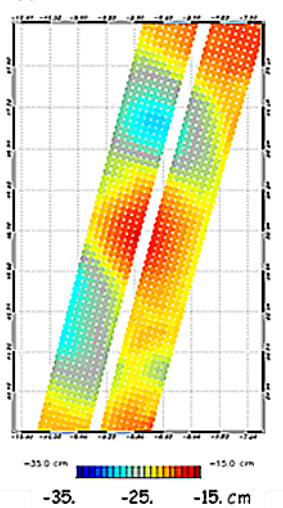

Figure 2. Satellite altimetry spatial coverage and wide-swath interferometer error. (a-c) Satellite altimetry spatial coverage during one assimilation cycle (5 days). (a) Jason-2, CryoSat-2 and Sentinel-3a, (b) Swath-1 and (c) Swath-1+Swath-2. (d-e) Across-swath error. (d) The curves displayed show the wide-swath instrumental error used to perform the OSSE2 and OSSE3 experiments, considering an across-swath horizontal resolution of $1 \mathrm{~km}$ (black line) and $7 \mathrm{~km}$ (red line); the blue curve shows the instrumental error used in OSSE4.

(e) Along-swath error given by the radar interferometer noise and (f) along swath simulated data.

\subsubsection{Satellite altimetry data}

In order to investigate the impact of different constellations of satellite altimeters, both conventional along-track and wide-swath altimetry measurements were considered. Conventional altimetry data were derived from sampling the NR over the theoretical tracks of the Jason-2, CryoSat-2 and Sentinel-3a satellite missions, with a sampling frequency of $1 \mathrm{~Hz}$ ( $\sim 7 \mathrm{~km}$ spatial sampling; e.g. Roblou et al., 2011). An observation white noise of $1 \mathrm{~cm}$ root mean square was simulated and added to these pseudo-observations. Using the same approach, wide-swath data were derived considering a 20.9-day repeat orbit at a spatial resolution of $7 \mathrm{~km}$ along and across the swath. In order to investigate the impact of multiple wide-swath altimeter missions, the data were derived by simulating two wide-swath altimeters, hereafter Swath-1 and Swath-2, obtained considering a 10-day shift in the orbits of the simulated missions. Figure 2 shows the spatial coverage of simulated satellite altimetry data over a 5-day period (analysis window) considering conventional nadir (Fig. 2a), along Swath-1 (Fig. 2b) and along Swath-1 and 2 (Fig. 2c) altimeter missions. The specifics for each satellite altimetry mission considered in this study are detailed in Table 2. 
Table 2. Satellite altimetry mission characteristics (https://earth.esa. int/web/eoportal/satellite-missions, last access: 18 October 2018). The columns show the following altimeter orbit parameters: repeat cycle (RC; expressed as days), footprint (FP) and cross-track separation (CTS; expressed as $\mathrm{km}$ ). The rows show the altimeters considered in this study: Jason-2 (J2), CryoSat-2 (C2), Sentinel-3a (S3; Donlon et al., 2012) and Swath-1. In Swath-1, CTS is the distance of consecutive ocean cross-overs points given by the overlap of an ascending and a descending pass (Esteban Fernandez et al., 2014).

\begin{tabular}{lrrr}
\hline & $\begin{array}{r}\text { RC } \\
(\text { days })\end{array}$ & $\begin{array}{r}\text { FP } \\
(\mathrm{km})\end{array}$ & $\begin{array}{r}\text { CTS } \\
(\mathrm{km})\end{array}$ \\
\hline J2 & 9.9 & 10 & 315 \\
C2 & 369 & 15 & $>7.5$ \\
S3 & 27 & 18 & 104 \\
Swath-1 & 20.9 & 120 & 500 \\
\hline
\end{tabular}

\subsubsection{Wide-swath altimetry data}

As previously mentioned, wide-swath altimetry observations were obtained by sampling the NR in such a way as to mimic wide-swath $\mathrm{SSH}$ measurements. A $7 \mathrm{~km}$ grid resolution was considered to be consistent with the horizontal resolution of the AR configuration. Wide-swath altimetry measurements can be characterized by correlated and uncorrelated errors. Several studies have given a detailed description of wideswath (SWOT-like) altimetry errors (e.g. Esteban Fernandez et al., 2014; Dibarboure and Ubelmann, 2014; Gaultier et al., 2016; Ubelmann et al., 2015; Ruggiero et al., 2016). Aware of the importance of a full characterization of the errors to exploit the information coming from wide-swath altimetry data (Ubelmann et al., 2017), and as this work is a first attempt to investigate their contribution to the ocean analyses and forecasts, we focus only on the instrumental uncorrelated errors due to the radar interferometer (thermal noise) and on their cross-track variability. Figure $2 \mathrm{~d}$ shows the standard deviation of the random error obtained considering different radar interferometer configurations and across-swath horizontal resolutions of 1 and $7 \mathrm{~km}$. In this sense, it is important to notice that the error has marked spatial variability across the swath, reaching the highest values at the edges and the lowest values near the inner part of the swath.

The measurement errors caused by the radar interferometer were defined in collaboration with TAS, a contractor of radar altimeters for EO in Europe. In this study, the error due to a Ku-band klystron dual receive antenna (DRA) was considered and a cross-track spatial resolution of $7 \mathrm{~km}$ was selected to be consistent with the resolution of the simulated satellite altimetry data.

\section{Experimental set-up: OSSEs}

In this section we describe the design of the OSSEs performed to investigate the impact of wide-swath altimetry data assimilation in an ocean monitoring and forecasting system in the IBI region.

First, a reference experiment, hereafter referred to as OSSE0, was performed considering the AR configuration but without any synthetic observations. Four other different OSSEs were carried out varying the type and number of altimeter missions considered. To assess how the constellation of nadir altimeters constrain the ocean analysis and forecast, an experiment was performed exclusively considering conventional nadir altimeters (Jason-1, CryoSat-2, Sentinel3a), hereafter referred to as OSSE1, assuming an instrumental error of $1 \mathrm{~cm}$. A second experiment, hereafter referred to as OSSE2, was performed considering nadir altimeters and Swath-1 data to address the question of the impact of future SSH measurements based on both nadir and wide-swath altimeter missions. As previously mentioned, SWOT-like data have a temporal resolution that does not allow the evolution of mesoscale structures to be resolved correctly. In order to investigate the impact of the repeat cycle of wide-swath altimetry data, in the OSSE3 experiment an additional wideswath altimeter was considered relative to OSSE2. This first series of OSSEs (OSSE2 and OSSE3) was performed assimilating wide-swath altimetry data simulated assuming a radar interferometer error that ranged between $0.8 \mathrm{~cm}$ in the inner part of the swath and $2 \mathrm{~cm}$ at the outer edges. The instrumental error was selected, in close collaboration with TAS, to consider less stringent noise requirements compared to the NASA/CNES SWOT mission. In particular, we considered an instrumental error four times larger than the error prescribed for the Ka-band Radar Interferometer (KaRIN) onboard the SWOT mission (TAS technical report). Figure $2 \mathrm{~d}$ shows the across swath error obtained considering a spatial resolution at both $1 \mathrm{~km}$ (black line) and $7 \mathrm{~km}$ (red line). In order to investigate the sensitivity of the ocean analysis and forecasting system to the error of a wide-swath altimetry instrument, a dedicated OSSE, hereafter referred to as OSSE4, was performed considering a satellite constellation as in OSSE3 but assuming a radar interferometer error of one-half the order of magnitude $(0.4-1 \mathrm{~cm})$ with respect to the other OSSEs $(2 \times$ KaRIN error). The error values in OSSE4 represent one of the solutions analysed by TAS, as part of this ESA study, to develop European wide-swath altimetry concepts. The experimental set-up used in this study is detailed in Table 3 .

\section{Impact on sea-level analyses and forecasts}

In this section we compare the SSH in the different OSSEs, with the "truth" SSH given by the NR. Figure 3 shows the SSH variance in the NR, computed over the period from February to December 2009. The IBI region is characterized by a relatively steep bathymetric slope separating the deep ocean from the shelf (Maraldi et al., 2013). On the continental shelves, the barotropic component of the SSH has a dom- 
Table 3. OSSEs experimental set-up. The rows show the names of the relevant experiments, whereas the columns detail the observations considered in the analysis. Column 1 shows the nadir altimeters considered in the OSSEs: Jason-2 (J2), CryoSat-2 (C2), Sentinel-3a (S3). The last column shows the instrumental error used to simulate the altimetry data. OSSE2-OSSE4 represent the range of across swath errors considered for the wide-swath altimetry data. The sections in parentheses represent the following: "Free" is the reference simulation without data assimilation; "3N" denotes the three nadir altimeters; " $1 \mathrm{~S}$ " is one wide-swath; " $2 \mathrm{~S}$ " is two wide-swath; and "LE" is lower radar interferometer error. In sections in brackets represent the order of magnitude of the wide-swath altimetry error selected in the OSSEs with respect to the error of the KaRIN instrument (NASA/CNES SWOT mission).

\begin{tabular}{lccccll}
\hline & J2, C2, S3 & Swath-1 & Swath-2 & $T \& S$ & SST & Error $(\mathrm{cm})$ \\
\hline OSSE0 (Free) & & & & & & \\
OSSE1 (3N) & YES & & & YES & YES & 1 \\
OSSE2 (3N $+1 S)$ & YES & YES & & YES & YES & $0.8-2[4 \times$ KaRIN $]$ \\
OSSE3 $(3 N+2 S)$ & YES & YES & YES & YES & YES & $0.8-2[4 \times$ KaRIN $]$ \\
OSSE4 $(3 \mathrm{~N}+2 \mathrm{~S}+$ LE) & YES & YES & YES & YES & YES & $0.4-1[2 \times$ KaRIN $]$ \\
\hline
\end{tabular}

inant signature. Preliminary findings of this work showed that this kind of variability was also captured in the reference simulation (OSSE0), without data assimilation, while in the deeper areas of the ocean it was not accurately reproduced and the variance of the error was larger than $50 \%$ of the variance of the NR (not shown). To assess the results, we considered the relative variance $\mathrm{VAR}^{*}$ defined (in terms of percentage) as follows:

$\operatorname{VAR}^{*}=100 \frac{\operatorname{VarError}\left(\mathrm{OSSE}_{k}\right)}{\operatorname{Var}(\mathrm{NR})}$,

where VarError is the variance of the error obtained by comparing a given OSSE with the NR, $k$ refers to the $k$ th experiments and $\operatorname{Var}(\mathrm{NR})$ is the variance of the signals in the NR. In particular VarError and $\operatorname{Var}(\mathrm{NR})$ are spatial maps of temporal variance, which (considering SSH data), are defined as

VarError $=\frac{\sum_{t=0}^{t=T}\left(\operatorname{SSH}_{\mathrm{OSSE}_{k}}(x, y, t)-\operatorname{SSH}_{\mathrm{NR}}(x, y, t)\right)^{2}}{n_{\mathrm{t}}}$ $-\left(\frac{\sum_{t=0}^{t=T}\left(\operatorname{SSH}_{\mathrm{OSSE}_{k}}(x, y, t)-\operatorname{SSH}_{\mathrm{NR}}(x, y, t)\right)}{n_{\mathrm{t}}}\right)^{2}$

$\operatorname{Var}(\mathrm{NR})=\frac{\sum_{t=0}^{t=T} \operatorname{SSH}_{\mathrm{NR}}(x, y, t)^{2}}{n_{\mathrm{t}}}-\left(\frac{\sum_{t=0}^{t=T} \operatorname{SSH}_{\mathrm{NR}}(x, y, t)}{n_{\mathrm{t}}}\right)^{2}$,

where $T$ is the last temporal record and $n_{\mathrm{t}}$ the number of temporal records considered.

In the following part of this section, the results are also presented in terms of the contribution of wide-swath altimetry data to the reduction of error $\left(\mathrm{ER}^{*}\right)$, both in ocean analysis and forecasting. In order to assess the impact of future satellite missions with respect to the current constellation of

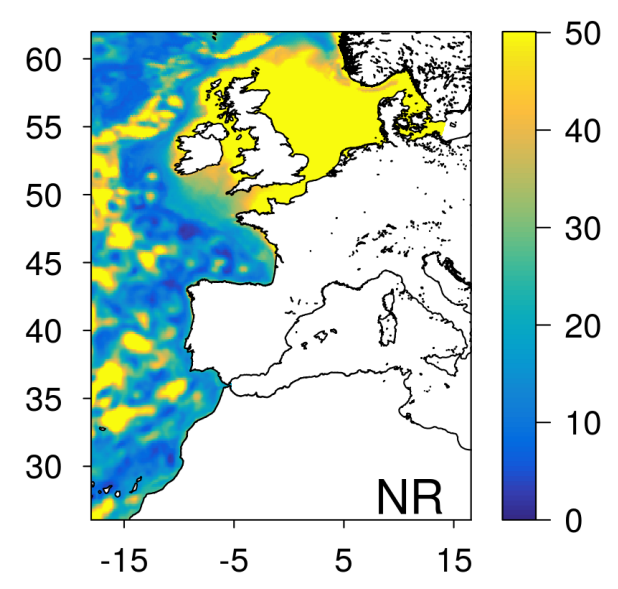

Figure 3. $\mathrm{SSH}$ variance (in $\mathrm{cm}^{2}$ ) in the NR over the period from February to December 2009.

nadir altimeters, $\mathrm{ER}^{*}$ is defined as the percentage decrease of the error with respect to OSSE1, i.e.

$\mathrm{ER}^{*}=100 \frac{\text { VarError(OSSE1) }- \text { VarError }\left(\mathrm{OSSE}_{k}\right)}{\text { VarError(OSSE1) }}$,

where VarError is defined as in Eq. (1), and $k$ refers to the $k$ th experiments, with $k=2, \ldots, 4$. A value of $50 \%$ means that the variance of the error in the $k$ th experiment has halved with respect to OSSE1.

Wide-swath altimetry data are expected to contribute significantly to resolving mesoscale and sub-mesoscale variability in the ocean, which can have different spatial scales defined by the Rossby radius of deformation in the different regions of the ocean. As shown in Hallberg (2013), over the shelf in the Celtic and North seas a higher horizontal resolution $\left(1 / 50^{\circ}\right)$ is needed to resolve the first baroclinic instability mode than the one used in the OSSEs $\left(1 / 12^{\circ}\right)$, which is nonetheless suitable for resolving the ocean dynamics in the Atlantic. Thus, in our configurations we expect to observe the contribution of altimetry data in the OSSEs more clearly in the open ocean than over the continental shelf. In 
order to take into account the effects of the SSH barotropic component and of the spatial resolution over the shelves, the results in the OSSEs were assessed both over the entire IBI domain and considering the ocean areas with a bathymetry deeper than $200 \mathrm{~m}$ (Table 4), which is the isobath that typically represents the separation between the continental slope and shelf in the bathymetry adopted by the OGCMs used in the OSSEs (Maraldi et al., 2013).

In the experiment that considers only nadir altimeters (OSSE1), the error regarding SSH in ocean analysis is $20 \%-30 \%$ of the variance of the SSH signal in the NR (VAR* in Table 4). Large errors were observed in occurrence of the main features of the ocean circulation in the IBI region, both in the northern (e.g. North Atlantic Drift) and southern part of the domain (e.g. Azores Current), as well as in the Bay of Biscay.

One of the most significant results of this study concerns the impact of a constellation of satellites combining nadir altimeters and one wide-swath instrument (OSSE2). Comparing the SSH in ocean analysis with the "truth" data, the results showed a significant positive impact on the system; a reduction of the variance of the error $\left(\mathrm{ER}^{*}\right)$ of up to $\sim 30 \%$ was also observed with respect to the error observed assimilating the data of a constellation of three conventional altimeters (Fig. 4). It is interesting to note that, if the shelf areas were excluded, the variance of the error increased in OSSE1, while in the experiments with wide-swath data a similar degree of error was observed over the whole domain (VarError in Table 4); these findings underline the impact of future measurements in the open ocean. As a consequence, the ER* in OSSE2 for ocean areas with a depth greater than $200 \mathrm{~m}$ was $\sim 35 \%$. The impact of wide-swath altimetry measurements can be noticed over the entire spatial domain in particular in the areas of the ocean characterized by the signature of the North Atlantic, Azores and Canary currents and in the occurrence of mesoscale eddies in the Bay of Biscay, where large errors were observed when only nadir altimeters were considered.

VAR $^{*}$ was also $6 \%$ lower for OSSE2 than for OSSE1. A larger impact was observed in the ocean forecast (Fig. 5), where the ER* increased by about $\sim 20 \%$, considering the last (fifth) day of ocean forecast (Table 5). When nadir altimeters were combined with a constellation of two wideswath altimeters (OSSE3) the impact on the ocean analysis and forecasting system was even more significant, with an $\mathrm{ER}^{*}$ of approximately $40 \%-45 \%$ considering the entire IBI domain. A comparison of the results of OSSE3 and OSSE2 shows the impact of the higher repeat cycle of wide-swath data. A difference of $\sim 10 \%$, in terms of ER*, was observed considering the data of two wide-swath missions in OSSE3, with respect to those obtained assimilating a single wideswath altimeter in OSSE2. The positive impact observed was mainly due to improvements in the representation of SSH variability in the Bay of Biscay and in the occurrence of the Azores Current (Fig. 6). Comparing OSSE2 and OSSE3, it

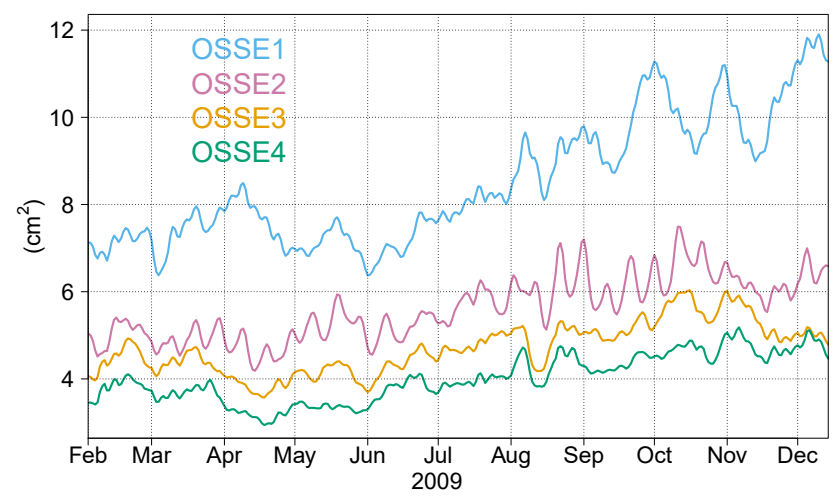

Figure 4. The temporal evolution of the SSH error variance in the ocean analysis over the period from February to December 2009. Results obtained by comparing the SSH of the ocean analysis in the OSSE1 (blue line), OSSE2 (purple line), OSSE3 (orange line) and OSSE4 (green line) experiments with the data from the NR considering the ocean areas with a bathymetry deeper than $200 \mathrm{~m}$. OSSE0 (not shown) ranged between 25 and $35 \mathrm{~cm}^{2}$.

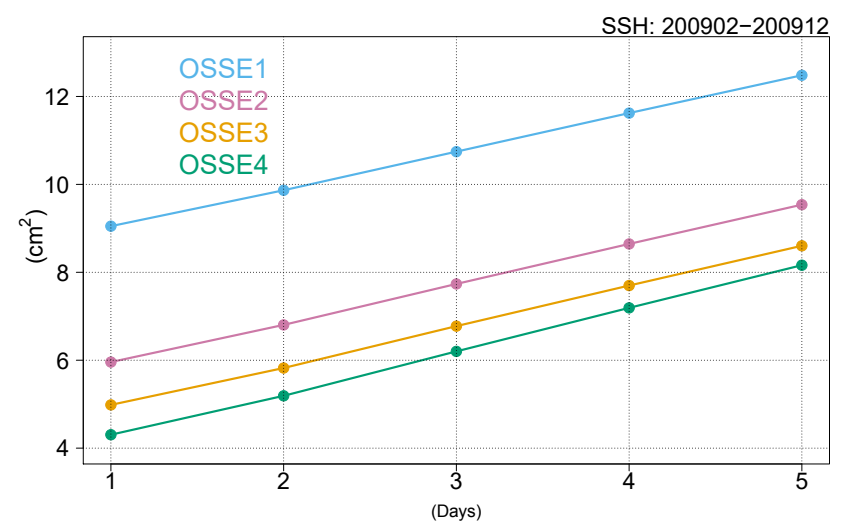

Figure 5. Variance of the error for each day of forecast (5 days) considering the SSH, in regions with a bathymetry deeper than $200 \mathrm{~m}$, over the period from February to December 2009. The legend for the OSSEs is as in Fig. 4;

is also interesting to note the impact on the forecasting of the SSH. A constellation of two wide-swath altimeters shows a significant $\mathrm{ER}^{*}(\sim 28 \%)$ in the ocean forecast until the fifth day of the forecast, which almost corresponds to the error reduction observed on the first day of the forecast (Table 5) considering only a single wide-swath altimeter (29\%).

Examining the sensitivity of the system to the instrumental error of wide-swath data, a smaller radar interferometer noise was used in OSSE4 $(0.4-1 \mathrm{~cm})$ relative to the error used in other OSSEs. The results showed a larger ER*, of the order of $7 \%-8 \%$ (Fig. 6), with respect to the experiment considering the same constellation of satellite altimeters (OSSE3) but a larger instrumental error $(0.8-2 \mathrm{~cm})$. OSSE4 showed a further improvement in representing the ocean dynamics due to the main ocean currents and mesoscale structures which characterize the SSH variability in the IBI region. 
Table 4. Ocean analysis statistics considering the SSH fields during the year 2009. Column 1 represents the ocean analysis variance of error with respect to the NR (VarError; $\mathrm{cm}^{2}$ ). Column 2 represents the reduction of the variance of the error in the ocean analysis (ER; \%), with respect to OSSE1 $(3 \mathrm{~N})$. Column 3 shows the ratio of the variance of the error in each experiment and the variance of the SSH signal in the NR (VAR*; \%). Columns 4-6 are the same as columns 1-3, but exclude the shelf areas shallower than $200 \mathrm{~m}(\mathrm{e} . \mathrm{g}$. ER $>200 \mathrm{~m}$; \%). The abbreviations in parentheses are defined in the caption of Table 3.

\begin{tabular}{lcccrcc}
\hline & $\begin{array}{c}\text { VarError } \\
\left(\mathrm{cm}^{2}\right)\end{array}$ & $\begin{array}{c}\text { ER } \\
(\%)\end{array}$ & $\begin{array}{r}\text { VAR }^{*} \\
(\%)\end{array}$ & $\begin{array}{r}\text { VarError }_{>} 200 \mathrm{~m} \\
\left(\mathrm{~cm}^{2}\right)\end{array}$ & $\begin{array}{c}\mathrm{ER}_{>200 \mathrm{~m}} \\
(\%)\end{array}$ & $\begin{array}{c}\text { VAR }_{>}^{*} 200 \mathrm{~m} \\
(\%)\end{array}$ \\
\hline OSSE1(3N) & 7.7 & - & 19 & 8.5 & - & 34 \\
OSSE2 (3N + 1S) & 5.4 & 30 & 13 & 5.6 & 34 & 22 \\
OSSE3 (3N+2S) & 4.7 & 39 & 12 & 4.7 & 45 & 19 \\
OSSE4 (3N + 2S + LE) & 4.2 & 46 & 10 & 4 & 53 & 16 \\
\hline
\end{tabular}

Table 5. SSH ocean forecast error statistics. Columns 1-3 represent the reduction of the variance of error in the ocean forecast $\left(\mathrm{ER}_{\mathrm{f}}\right)$, with respect to OSSE1 $(3 \mathrm{~N})$ on the first, third, and fifth day of forecast. Columns 4-6 are the same as columns 1-3, but exclude the shelf areas shallower than $200 \mathrm{~m}$ (e.g. $1 \mathrm{st}_{>200 \mathrm{~m}}$ ). The legend for the OSSEs is as in Fig. 4. Statistics obtained considering the period from February to December 2009. Values are expressed as percentages.

\begin{tabular}{lcccccc}
\hline & $\mathrm{ER}_{\mathrm{f}} 1 \mathrm{st}$ & $\mathrm{ER}_{\mathrm{f}} 3 \mathrm{rd}$ & $\mathrm{ER}_{\mathrm{f}} 5 \mathrm{th}$ & $\mathrm{ER}_{\mathrm{f}} 1 \mathrm{st}>200 \mathrm{~m}$ & $\mathrm{ER}_{\mathrm{f}} 3 \mathrm{rd}_{>200 \mathrm{~m}}$ & $\mathrm{ER}_{\mathrm{f}} 5 \mathrm{th}_{>} 200 \mathrm{~m}$ \\
\hline OSSE2 $(3 \mathrm{~N}+1 \mathrm{~S})$ & 29 & 25 & 21 & 34 & 28 & 24 \\
OSSE3 $(3 \mathrm{~N}+2 \mathrm{~S})$ & 39 & 33 & 28 & 45 & 37 & 31 \\
OSSE4 $(3 \mathrm{~N}+2 \mathrm{~S}+\mathrm{LE})$ & 45 & 37 & 31 & 52 & 42 & 35 \\
\hline
\end{tabular}

Table 6. Spectral analysis. Columns 2-4 represent the error reduction (\%) with respect to OSSE0 (control simulation) at different spatial scales. Columns 5-7 denote spectral coherence (0.8-0.4) in the OSSEs; the values show the spatial scale (expressed as km) at which the coherence falls below $0.8,0.6$ and 0.4 .

\begin{tabular}{|c|c|c|c|c|c|c|}
\hline & \multicolumn{3}{|c|}{$\mathrm{ER}_{\text {spec }}(\%)$} & \multicolumn{3}{|c|}{$C_{\text {spec }}$} \\
\hline & $200-400 \mathrm{~km}$ & $100-200 \mathrm{~km}$ & $50-100 \mathrm{~km}$ & 0.8 & 0.6 & 0.4 \\
\hline OSSE1 $(3 N)$ & 79 & 64 & 10 & $280 \mathrm{~km}$ & $155 \mathrm{~km}$ & $125 \mathrm{~km}$ \\
\hline OSSE2 $(3 \mathrm{~N}+1 \mathrm{~S})$ & 89 & 79 & 28 & $170 \mathrm{~km}$ & $125 \mathrm{~km}$ & $105 \mathrm{~km}$ \\
\hline OSSE3 $(3 \mathrm{~N}+2 \mathrm{~S})$ & 89 & 81 & 30 & $165 \mathrm{~km}$ & $120 \mathrm{~km}$ & $95 \mathrm{~km}$ \\
\hline OSSE4 $(3 N+2 S+L E)$ & 91 & 84 & 38 & $150 \mathrm{~km}$ & $115 \mathrm{~km}$ & $90 \mathrm{~km}$ \\
\hline
\end{tabular}

In particular, the largest $\mathrm{ER}^{*}(\sim 50 \%)$ was observed in OSSE4 and the errors represent the smallest portion $(10 \%-$ $15 \%$ ) of the "observed" ocean variability (VAR*).

The results of the impact of wide-swath altimetry data on the SSH in ocean analysis are summarized in Table 4.

\section{Spectral analysis and coherence}

In this section we describe the results obtained in the OSSEs in terms of the representation of ocean dynamics, looking at the errors over different spatial scales of variability.

The impact of wide-swath altimetry data in the OSSEs was assessed by a power spectra comparison, considering an open ocean area representative of the North Atlantic Drift $\left(19^{\circ} \mathrm{W}-10^{\circ} \mathrm{W}, 46^{\circ} \mathrm{N},-55^{\circ} \mathrm{N}\right)$. This region is defined as an intermediate mesoscale variability region in the global ocean (Garçon et al., 2001) and is one of the regions which show the highest variability of ocean circulation within the IBI do- main. In particular, we focus here on the impact of wideswath altimetry on the SSH at different spatial scales. A wavelength window between 12 and $400 \mathrm{~km}$ was selected in order to clearly represent the energy content of the SSH signal in the sub-domain, given the spatial resolution of the OGCM used to perform the OSSEs. The analysis of spectra in a variance preserving form (Thomson and Emery, 2014) is shown in Fig. 7. The power spectra of the error (Fig. 7b) clearly show the differences among the OSSEs. Here the reduction of the error at the different wavelength $\left(E_{\text {spec }}\right)$ is defined as the percentage decrease of the error with respect to OSSE0 (Table 6), in order to assess also the impact of nadir altimeters.

Considering nadir altimeters (blue curve), the impact on ocean analysis is noticeable at spatial scales down to $100 \mathrm{~km}$, but the impact is weaker at wavelengths of $50 \mathrm{~km}$. An $\mathrm{ER}_{\text {spec }}$ of up to $60 \%$ was observed at wavelengths between 100 and $200 \mathrm{~km}$. Significantly larger contributions were ob- 

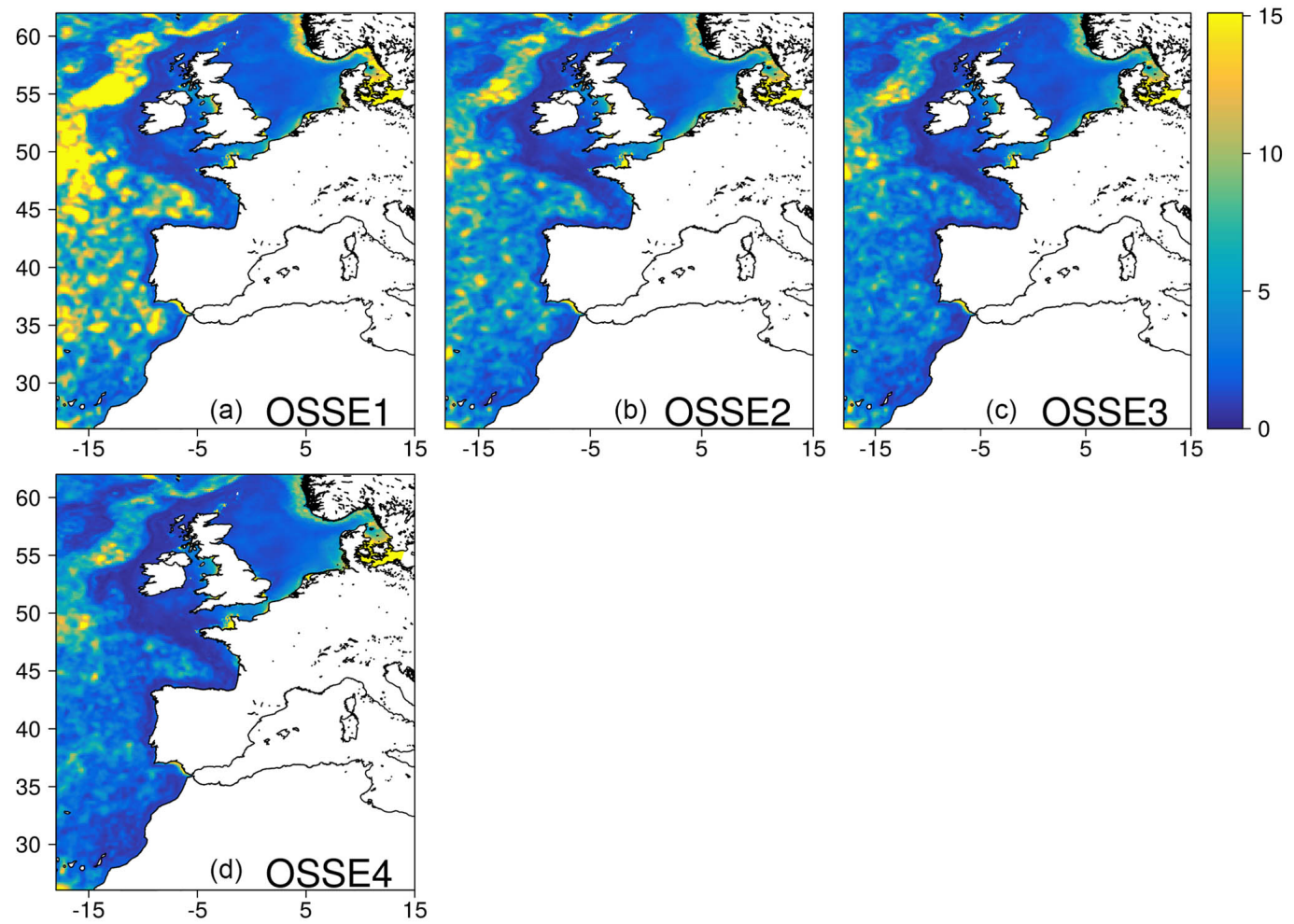

Figure 6. Maps of the variance of SSH error in the ocean analysis over the IBI domain during the period from February to December 2009. The results are obtained by comparing the SSH of the NR with the ocean analysis of the OSSE1 (a), OSSE2 (b), OSSE3 (c) and OSSE4 (d) experiments. Values expressed as square centimetres $\left(\mathrm{cm}^{2}\right)$.

(a) Error power spectrum

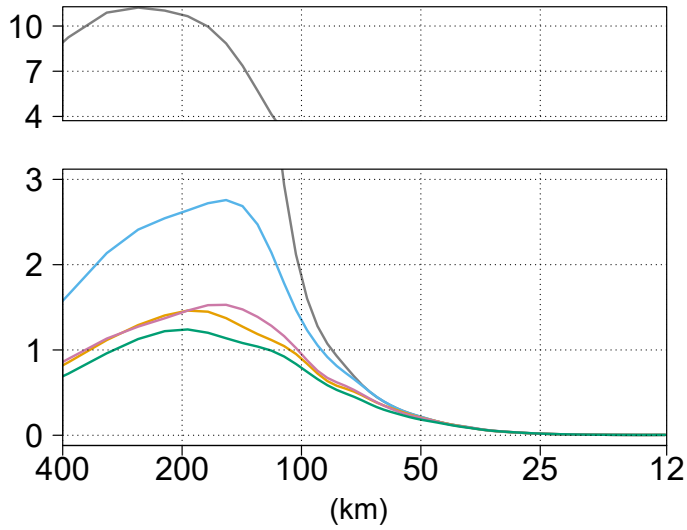

(b) Coherence

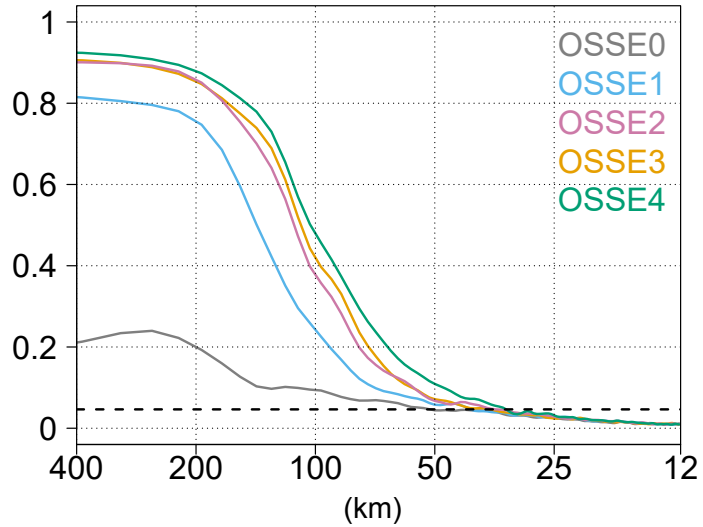

Figure 7. Spectral Analysis of the SSH signals in the OSSEs considering an open ocean region $\left(-19^{\circ} \mathrm{W},-10^{\circ} \mathrm{W} ; 46^{\circ} \mathrm{N}, 55^{\circ} \mathrm{N}\right)$ representative of the North Atlantic Drift, during the period from February to December 2009. The results for the OSSE0 (gray lines), OSSE1 (blue lines), OSSE2 (purple lines), OSSE3 (orange lines) and OSSE4 (green lines) experiments, are shown in the spectral window between 400 and $12 \mathrm{~km}$. (a) Power spectra of the SSH error with respect to the NR; the spectra are shown in a variance preserving form $\left(\mathrm{cm}^{2}\right) .(\mathbf{b})$ Spectral coherence in the OSSEs with respect to the NR; the black dashed line shows the $95 \%$ confidence interval (Thomson and Emery, 2014).

served considering wide-swath altimetry data $\left(\mathrm{ER}_{\mathrm{spec}}\right.$ up to $>80 \%$ ). Comparing the results in OSSE1 with those obtained in the other experiments (Fig. 7a; Table 6), the reduction of error at these scales ranged between $40 \%$ and $55 \%$. This is in agreement with Dufau et al. (2016) who, investigat- ing the resolution capability of present and future altimetry missions, observed that wide-swath altimetry will provide an unprecedented insight into mesoscale ocean dynamics with respect to along-track data. Here it is also interesting to note that the difference between OSSE2 and OSSE3 (purple and 
orange lines) is small, but the difference between OSSE2 and OSSE4 (green line) is significant, showing the impact of the higher repeat cycle of the SSH measurements and the sensitivity of the system to the error of a wide-swath instrument.

The contribution of wide-swath altimetry data was also significant at spatial scales smaller than $100 \mathrm{~km}$, which was not the case when only nadir altimeters were considered. In particular, considering wavelengths between 50 and $100 \mathrm{~km}$, wide-swath altimetry data showed the largest contribution, with respect to along-track data. At these spatial scales, the $\mathrm{ER}_{\text {spec }}$ in OSSE1 was the lowest $(10 \%)$ observed in the spectral analysis. Combining nadir altimeters with one wideswath instrument (OSSE2), the results showed an $\mathrm{ER}_{\text {spec }}$ of $28 \%$. The introduction of a second wide-swath altimeter in OSSE3, assuming the same instrumental error as that used in OSSE2, showed a small further reduction of error $\left(\mathrm{ER}_{\text {spec }} \sim 30 \%\right)$. Conversely, considering a lower radar interferometer induced error in OSSE4 enhanced the system, making it capable of better resolving ocean dynamics at these spacial scales, and the highest $\mathrm{ER}_{\text {spec }}(>38 \%)$ was observed, underlining the sensitivity of the system to error in wide-swath measurements.

A coherence analysis (Thomson and Emery, 2014) was also performed to investigate the reliability of the SSH signal in the OSSEs at the different spatial scales, with respect to the NR (Fig. 7b). Spectral coherence is typically defined as the correlation between two signals as a function of wavelength (Ubelmann et al., 2015; Ponte and Klein, 2013; Klein et al., 2004). The spectral coherence between the SSH signals in the NR and in the OSSEs is defined as follows:

$C_{\text {spec }}=\frac{\mathrm{Cr}_{\mathrm{S}}\left(\mathrm{NR}, \mathrm{OSSE}_{k}\right)}{S(\mathrm{NR}) S\left(\mathrm{OSSE}_{k}\right)}$,

where $\mathrm{Cr}_{\mathrm{s}}$ and $S$ represent the cross-spectral density and spectral density, respectively, of the signals and $k$ refers to the $k$ th experiment.

Differences between the OSSEs in terms of spectral coherence can be seen down to spatial scales between 50 and $100 \mathrm{~km}$. The assimilation of wide-swath altimetry data significantly increased the coherence between the SSH signals, compared with the experiment that only considered nadir altimeters. At the large scale $(200-400 \mathrm{~km})$, the coherence between the SSH signals was fairly high $(>0.8)$ in all of the OSSEs. Considering the coherence values at relevant spatial scales, it is possible to compare the results in each experiment, as shown in Table 6. In particular, a different coherence value observed at the same length scales in the OSSEs provides evidence about the increased (decreased) level of reliability obtained considering (neglecting) a given observing system. At spatial scales between 100 and $200 \mathrm{~km}$, the coherence increased by $20 \%$ when considering one wide-swath and the nadir altimeters (OSSE2), compared to OSSE1. Similar values were observed for two wide-swath altimeters in OSSE3. Examining the sensitivity of the system to radar interferometer induced error, the observing system designed in
OSSE4 had the most significant impact on the spectral coherence in ocean analysis at these spatial scales, relative to OSSE1 $(>20 \%)$. At small scales $(<90 \mathrm{~km})$ the coherence was lower than 0.4 in all the experiments. Aware of the limited significance of low coherence values $(<0.5)$, we compare the results obtained in the OSSEs here in order to obtain a qualitative assessment of the impact of the forthcoming altimeters on spatial scales smaller than $100 \mathrm{~km}$. At these wavelengths the coherence in OSSE1 was lower in all cases than in the other OSSEs, and the system was sensitive to the higher repeat cycle of the wide-swath measurements considered: when the data of one (OSSE2) and two (OSSE3) wideswath altimeters were included, the coherence of the $\mathrm{SSH}$ signals in the ocean analysis increased accordingly. The difference between the results of OSSE3 and OSSE4 was not significant ( $C_{\text {spec }}$ ranged between 0.2 and 0.4 ), even though greater qualitative coherence of the SSH signals due to more "accurate" wide-swath altimeters (Fig. 7b, green line) was observed down to spatial scales smaller than $70 \mathrm{~km}$.

These results can be qualitatively extended to ocean forecasting over the same spatial domain (not shown).

\section{Impact on velocity fields}

In this section we compare the contribution of wide-swath altimetry to the representation of the ocean circulation in the IBI region for ocean analyses. In order to investigate the reliability of ocean circulation results obtained in the different experiments, a comparison of the zonal and meridional currents was carried out, both at the surface and in the water column (Table 7). Figure 8 shows the variance of the error obtained comparing the surface zonal velocities in the OSSEs with the same field in the NR over a 2-month period (August-September 2009). Figure 8a shows the variance of the error obtained considering conventional nadir altimeters (OSSE1); large errors were observed in the Atlantic. When wide-swath altimetry data were considered, a significant reduction of the error was observed, which was particularly evident in the North Atlantic Drift, in the occurrence of the Azores Current and in the Bay of Biscay. In particular, considering a constellation of three nadir and one wide-swath altimeters (OSSE2), an ER* up to $20 \%$ was observed, compared to the error observed considering only conventional altimeters. A larger impact on ocean circulation at the surface $\left(\mathrm{ER}^{*} \sim 28 \%\right)$ was observed when using a constellation of three nadir and two wide-swath altimeters (OSSE3). Considering more accurate wide-swath altimeters (OSSE4), the results showed a further reduction of the error in the domain $\left(\mathrm{ER}^{*} \sim 35 \%\right.$ ), mainly due to an improved representation of the North Atlantic Current. Small positive ER* differences $(2 \%-3 \%)$ were observed when only the ocean surface currents in the deep ocean $(>200 \mathrm{~m})$ were taken into account. A coherence analysis performed concerning the ocean currents (zonal and meridional) at the surface (not shown) confirmed 
Table 7. Error reduction (ER) of the zonal $(U)$ and meridional $(V)$ currents, with respect to nadir altimeters only (OSSE1). Columns $1-3$ represent the ocean current magnitude $\left(\mathrm{m} \mathrm{s}^{-1}\right)$ averaged at the surface $\left(M_{\mathrm{S}}\right), 100 \mathrm{~m}\left(M_{100 \mathrm{~m}}\right)$ and $300 \mathrm{~m}\left(M_{300 \mathrm{~m}}\right)$. Columns 4,6 and 7 denote the error reduction in the ocean analysis considering the zonal currents at surface $\left(U_{\mathrm{s}}\right)$, at $100 \mathrm{~m}\left(U_{100 \mathrm{~m}}\right)$ and at $300 \mathrm{~m}\left(U_{300 \mathrm{~m}}\right)$. Column 5 is the same as column 4 but excludes the shelf areas shallower than $200 \mathrm{~m}\left(U_{\mathrm{s}_{>200 \mathrm{~m}}}\right)$. Columns 8,10 and 11 are the same as columns 4,6 and 7 but consider meridional currents. Columns 9 is the same as column 5, but considers meridional currents $\left(V_{\mathrm{S}_{>}} 200 \mathrm{~m}\right)$. Values are expressed as percentages.

\begin{tabular}{cccccccccccc}
\hline & $M_{\mathrm{S}}$ & $M_{100 \mathrm{~m}}$ & $M_{300 \mathrm{~m}}$ & $\mathrm{ER}_{U_{\mathrm{s}}}$ & $\mathrm{ER}_{U_{\mathrm{s}_{>} 200 \mathrm{~m}}}$ & $\mathrm{ER}_{U_{100 \mathrm{~m}}}$ & $\mathrm{ER}_{U_{300 \mathrm{~m}}}$ & $\mathrm{ER}_{V_{\mathrm{s}}}$ & $\mathrm{ER}_{V_{\mathrm{s}_{>} 200 \mathrm{~m}}}$ & $\mathrm{ER}_{V_{100 \mathrm{~m}}}$ & $\mathrm{ER}_{V_{300 \mathrm{~m}}}$ \\
\hline OSSE2 & 0.12 & 0.1 & 0.1 & 21 & 23 & 23 & 23 & 23 & 25 & 24 & 24 \\
OSSE3 & 0.11 & 0.1 & 0.1 & 28 & 30 & 29 & 26 & 29 & 31 & 31 \\
OSSE4 & 0.12 & 0.1 & 0.1 & 35 & 37 & 34 & 30 & 38 & 41 & 36 & 32 \\
\hline
\end{tabular}
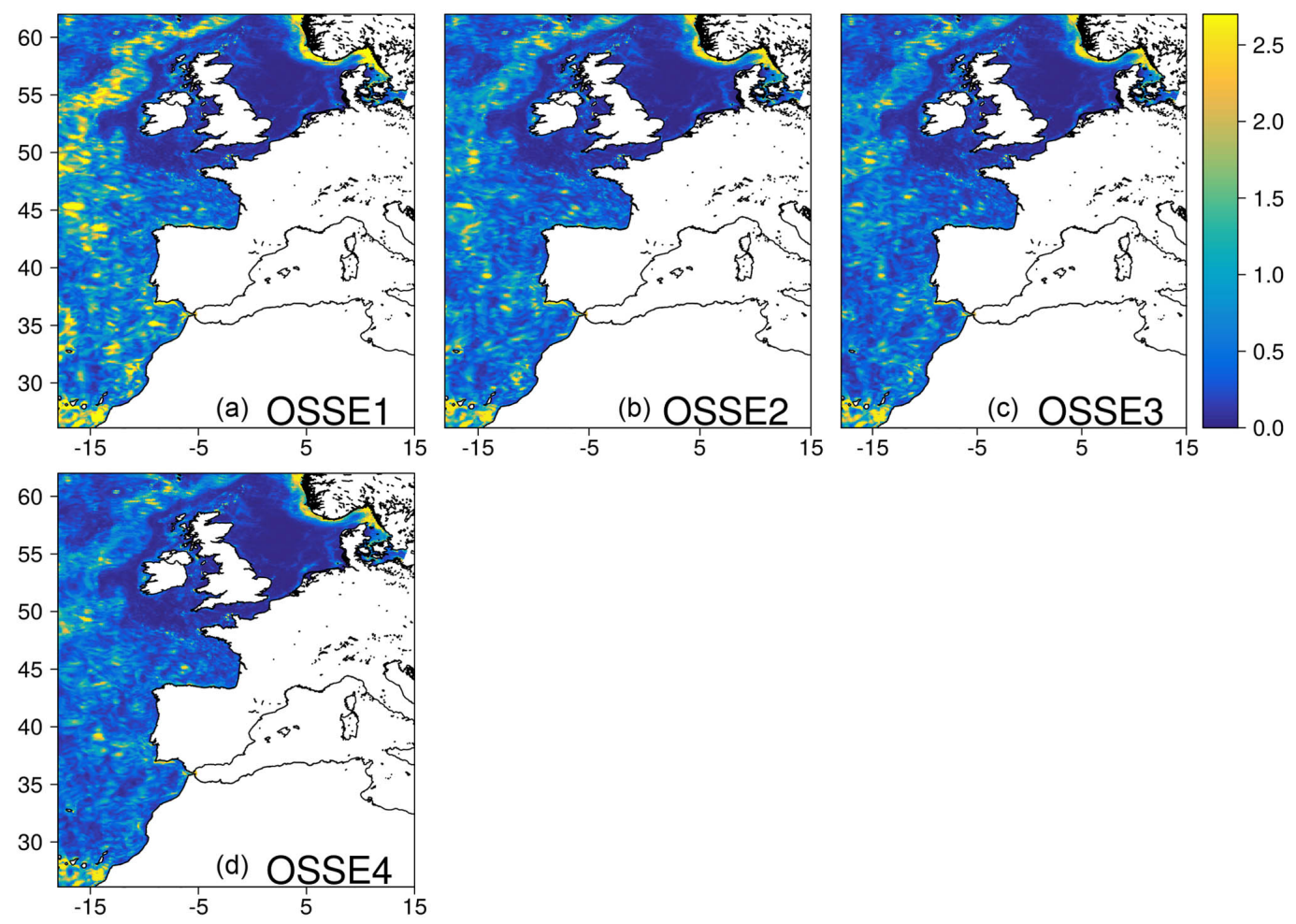

Figure 8. Ocean zonal currents at the surface: variance of misfits in the ocean analysis over the IBI domain during the period from August to September 2009. The results are obtained by comparing the zonal currents of the "truth" data with the ocean analysis in the OSSE1 (a), OSSE2 (b), OSSE3 (c) and OSSE4 (d) experiments. Values are expressed as $10^{-2} \mathrm{~m}^{2} \mathrm{~s}^{-2}$.

the results observed concerning the SSH fields. The results obtained for the zonal currents at the surface can also be extended to the meridional currents, and in general to the ocean currents in the water column, as shown in Fig. 9. The results of the comparison of the ocean currents in the OSSEs are summarized in Table 7.

\section{Summary and conclusions}

The contribution of wide-swath altimetry data to ocean analyses and forecasts was assessed in the IBI region over a 1year period (2009) by means of OSSEs. Five different exper- iments (four OSSEs and one reference simulation, OSSE0) were designed simulating different constellations of satellites, composed of nadir and wide-swath altimeters, and the results were compared with the NR. OSSE1 is representative of the current constellation of altimeters and considers simulated data from three nadir altimeters (Jason-2, CryoSat-2 and Sentinel-3a). Dedicated experiments performed for calibration purposes, prescribing a $3 \mathrm{~cm}$ observation error on along-track observations to mimic the present altimetric observing systems, showed results consistent with those derived using real data in OSEs designed to assess the impact of multiple along-track altimeters in CMEMS systems. 

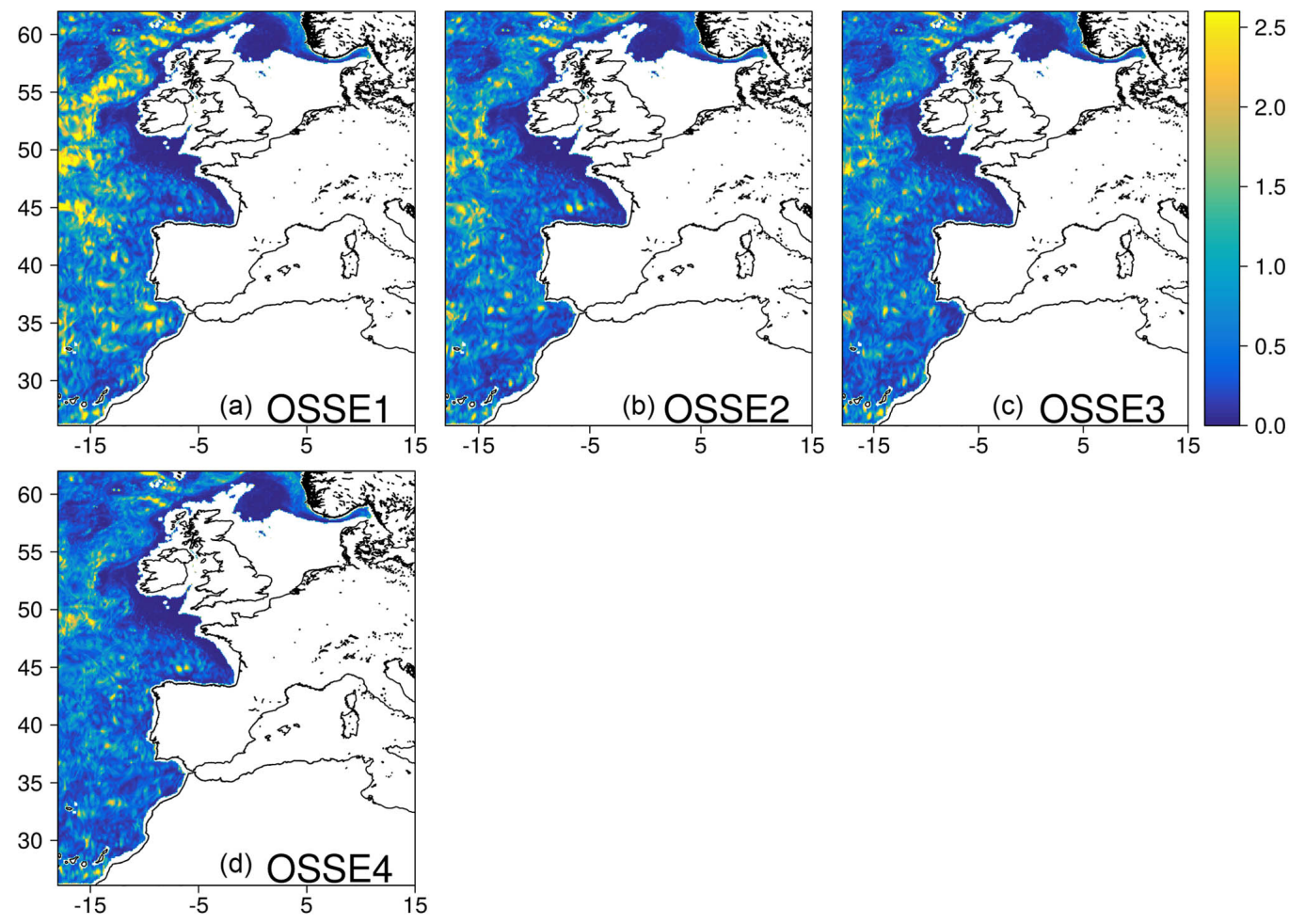

Figure 9. As in Fig. 8 but considering ocean meridional currents at a depth of $100 \mathrm{~m}$.

OSSE2 differs from OSSE1 due to the introduction of a wide-swath altimeter in the satellite constellation. The impact of the repeat cycle of wide-swath measurements was investigated in OSSE3, which included a further wide-swath mission, in addition to OSSE2. The sensitivity of the system to wide-swath radar interferometer error was investigated in OSSE4, considering a lower instrumental error $(0.4-1 \mathrm{~cm})$ than that used in the other experiments.

An initial result of this study concerns the reliability of the SSH signals that can be obtained by considering different constellations of altimeter missions. Wide-swath SSH measurements considerably reduced error in ocean analyses and forecasts. A constellation of two wide-swath altimeters (OSSE4) reduced the variance of SSH errors by more than $50 \%$ compared to three conventional nadir altimeters, mainly due to the improved representation of ocean mesoscale variability in areas where main ocean currents occur in the IBI region (e.g. North Atlantic and Azores currents). With respect to the SSH ocean forecasts, the most significant results were obtained when investigating the impact of two wide-swath altimeters. In particular the ER* given by a constellation of three nadir altimeters and one wide-swath mission $(3 \mathrm{~N}+1 \mathrm{~S})$ for the first day of forecast $(\sim 30 \%)$ is comparable to the $\mathrm{ER}^{*}$ obtained for the last (fifth) day of forecast when a second wide-swath altimeter $(3 \mathrm{~N}+2 \mathrm{~S})$ is included in the satellite constellation. The inclusion of a second wide-swath altimeter could have a strong implication for extending the temporal window in the ocean forecast. The ocean analysis and forecasting system used to perform the OSSEs was sensitive to the repeat cycle of wide-swath measurements and to the instrumental error caused by wideswath altimeters. The most significant results were obtained when considering a constellation of three nadir and two "accurate" wide-swath altimeters (OSSE4; instrumental error $0.4-1 \mathrm{~cm}$ ), which reduced the error in ocean analysis by up to $\sim 10 \%$ of the "observed" ocean variability (VAR*) in the (ocean) analysis.

When assessing the SSH signals in the OSSEs using power spectra comparison and coherence analysis with the NR in one of the most energetic sub-regions in the IBI domain (North Atlantic Drift), the results showed that wide-swath altimetry data significantly contribute $(40 \%-50 \%)$ to the resolution of ocean dynamics due to mesoscale variability. This is in agreement with Dufau et al. (2016), who observed that wide-swath altimetry will provide an unprecedented insight into mesoscale ocean dynamics, with respect to along-track data. A reduction of error and a higher coherence of the SSH signals can be observed down to wavelengths $<100 \mathrm{~km}$ when considering two accurate wide-swath altimeters within a future satellite constellation, relative to the current configuration. Similar results were also observed considering ocean forecasts and performing the same analysis on ocean currents at the surface. The information provided by wide-swath data at the surface is also applied, through error covariances, in 
the vertical dimension and has a considerable impact on the ocean circulation both at the surface and in the water column. Looking at the zonal currents and meridional currents at the surface and at depth, the error in the analysis was significantly reduced (by $30 \%$ ) with two wide-swath instruments in the satellite constellation, relative to nadir altimeters. In particular, a reduction of the error by $\sim 10 \%$ was observed on the ocean currents (up to $100 \mathrm{~m}$ ) considering a constellation of two "accurate" wide-swath altimeters (OSSE4), compared with wide-swath instruments with a larger observational error.

As already mentioned, the system used to assess the impact of wide-swath altimetry data is sensitive to the instrumental (uncorrelated) errors due to radar interferometer noise. Future constellations of nadir and "accurate" wideswath altimeters should have a dramatic impact for constraining CMEMS ocean analysis and forecasting systems and their applications.

This study is a first effort to quantify the impact of a constellation of wide-swath altimeters on ocean analyses and forecasts. In the future, OSSEs should be performed in regions characterized by high mesoscale variability (e.g. western boundary currents) to better assess the impact of measurement errors in regions with a large signal-to-noise ratio. The sensitivity of the results to the model spatial resolution should be assessed by performing OSSEs with a fully eddyresolving ocean model (e.g. $1 / 36^{\circ}$ ). Finally, a full and accurate characterization of wide-swath altimeter error spectra (Ubelmann et al., 2017) would allow the design of highly realistic OSSEs, improving the definition of the error covariances required to combine wide-swath altimetry data and OGCMs through data assimilation techniques.

Data availability. No data sets were used in this article.

Competing interests. The authors declare that they have no conflict of interest.

Acknowledgements. This work was supported by the European Space Agency (ESA) study on the potential role of wide-swath altimetry for the evolution of the European Union Copernicus programme (contract ESA-Mercator Ocean no. 4000117621/16/NL/FF/gp).

Edited by: John M. Huthnance

Reviewed by: two anonymous referees

\section{References}

Atlas, R., Hoffman, R. N., Ma, Z., Emmitt, G. D., Wood Jr., S. A., Greco, S., Tucker, S., Bucci, L., Annane, B., Hardesty, R. M., and Murillo, S.: Observing System Simulation Experiments (OSSEs) to Evaluate the Potential Impact of an Optical Autocovariance Wind Lidar (OAWL) on Numerical Weather Prediction, J. Atmos. Ocean. Tech., 32, 1593-1613, https://doi.org/10.1175/JTECH-D-15-0038.1, 2015.

Barnier, B., Madec, G., Penduff, T., Molines, J.-M., Treguier, A.M., Le Sommer, J., Beckmann, A., Biastoch, A., Böning, C., Dengg, J., Derval, C., Durand, E., Gulev, S., Remy, E., Talandier, C., Theetten, S., Maltrud, M., McClean, J., and De Cuevas, B.: Impact of partial steps and momentum advection schemes in a global ocean circulation model at eddy-permitting resolution, Ocean Dynam., 56, 543-567, https://doi.org/10.1007/s10236006-0082-1,, 2006.

Bell, M., Schiller, A., Traon, P.-Y. L., Smith, N., Dombrowsky, E., and Wilmer-Becker, K.: An introduction to GODAE OceanView, J. Oper. Oceanogr., 8, s2-s11, https://doi.org/10.1080/1755876X.2015.1022041, 2015.

Benkiran, M. and Greiner, E.: Impact of the Incremental Analysis Updates on a Real-Time System of the North Atlantic Ocean, J. Atmos. Ocean. Tech., 25, 2055-2073, https://doi.org/10.1175/2008JTECHO537.1, 2008.

Bloom, S. C., Takacs, L. L., da Silva, A. M., and Ledvina, D.: Data Assimilation Using Incremental Analysis Updates, Mon. Weather Rev., 124, 1256-1271, https://doi.org/10.1175/15200493(1996)124<1256:DAUIAU>2.0.CO;2, 1996.

Cabanes, C., Grouazel, A., von Schuckmann, K., Hamon, M., Turpin, V., Coatanoan, C., Paris, F., Guinehut, S., Boone, C., Ferry, N., de Boyer Montégut, C., Carval, T., Reverdin, G., Pouliquen, S., and Le Traon, P.-Y.: The CORA dataset: validation and diagnostics of in-situ ocean temperature and salinity measurements, Ocean. Sci., 9, 1-18, https://doi.org/10.5194/os9-1-2013, 2013.

Carrère, L., Lyard, F., Cancet, M., Guillot, A., and Picot, N.: FES 2014, a new tidal model - Validation results and perspectives for improvements, in: Proceedings of the ESA Living Planet Symposium 2016, 9-13 May 2016, Prague, Czech Republic, 2016.

Dee, D., Uppala, S., Simmons, A., Berrisford, P., Poli, P., Kobayashi, S., Andrae, U., Balmaseda, M., Balsamo, G., Bauer, P., Bechtold, P., Beljaars, A. C., van de Berg, L., Bidlot, J., Bormann, N., Delsol, C., Dragani, R., Fuentes, M., Geer, A. J., Haimberger, L., Healy, S. B., Hersbach, H., Hólm, E. V., Isaksen, L., Kållberg, P., Köhler, M., Matricardi, M., McNally, A. P., Monge-Sanz, B. M., Morcrette, J., Park, B., Peubey, C., de Rosnay, P., Tavolato, C., Thépaut, J., and Vitart, F.: The ERA-Interim reanalysis: Configuration and performance of the data assimilation system, Q. J. Roy. Meteorol. Soc., 137, 553-597, 2011.

Dibarboure, G. and Ubelmann, C.: Investigating the Performance of Four Empirical Cross-Calibration Methods for the Proposed SWOT Mission, Remote Sensing, 6, 4831-4869, https://doi.org/10.3390/rs6064831, 2014.

Dibarboure, G., Pujol, M.-I., Briol, F., Le Traon, P. Y., Larnicol, G., Picot, N., Mertz, F., and Ablain, M.: Jason-2 in DUACS: Updated System Description, First Tandem Results and Impact on Processing and Products, Mar. Geodesy, 34, 214-241, https://doi.org/10.1080/01490419.2011.584826, 2011. 
Donlon, C., Berruti, B., Buongiorno, A., Ferreira, M.-H., Féménias, P., Frerick, J., Goryl, P., Klein, U., Laur, H., Mavrocordatos, C., Nieke, J., Rebhan, H., Seitz, B., Stroede, J., and Sciarra, R.: The Global Monitoring for Environment and Security (GMES) Sentinel-3 mission, Remote Sens. Environ., 120, 37-57, https://doi.org/10.1016/j.rse.2011.07.024, 2012.

Ducet, N., Le Traon, P. Y., and Reverdin, G.: Global highresolution mapping of ocean circulation from TOPEX/Poseidon and ERS-1 and -2, J. Geophys. Res., 105, 19477-19498, https://doi.org/10.1029/2000JC900063, 2000.

Dufau, C., Orsztynowicz, M., Dibarboure, G., Morrow, R., and Le Traon, P.-Y.: Mesoscale resolution capability of altimetry: Present and future, J. Geophys. Res.-Oceans, 121, 4910-4927, https://doi.org/10.1002/2015JC010904, 2016.

Durand, M., Fu, L.-L., Lettenmaier, D. P., Alsdorf, D. E., Rodriguez, E., and Esteban-Fernandez, D.: The surface water and ocean topography mission: Observing terrestrial surface water and oceanic submesoscale eddies, Proc. IEEE, 98, 766-779, 2010.

Egbert, G. D. and Erofeeva, S. Y.: Efficient Inverse Modeling of Barotropic Ocean Tides, J. Atmos. Ocean. Tech., 19, 183-204, https://doi.org/10.1175/15200426(2002)019<0183:EIMOBO>2.0.CO;2, 2002.

Errico, R. M., Yang, R., Privé, N. C., Tai, K.-S., Todling, R., Sienkiewicz, M. E., and Guo, J.: Development and validation of observing-system simulation experiments at NASA's Global Modeling and Assimilation Office, Q. J. Roy. Meteorol. Soc., 139, 1162-1178, https://doi.org/10.1002/qj.2027, 2013.

Esteban Fernandez, D., Pollard, B., Vaze, P., and Abelson, R.: Swot Project Mission Performance and Error Budget, Tech. Rep. JPL D-79084, p. 83, https://swot.jpl.nasa.gov/ science/resources (last access: 18 October 2018), 2014.

Fu, L.-L. and Chelton, D. B.: Chapter 2 Large-Scale Ocean Circulation, in: International Geophysics, Vol. 69, edited by: Fu, L.-L. and Cazenave, A., Academic Press, https://doi.org/10.1016/S0074-6142(01)80147-9, 2001.

Fu, L.-L. and Ferrari, R.: Observing Oceanic Submesoscale Processes From Space, Eos Trans. Am. Geophys. Union, 89, 488488, https://doi.org/10.1029/2008EO480003, 2008.

Fu, L.-L., Alsdorf, D., Rodriguez, E., Morrow, R., Mognard, N., Lambin, J., Vaze, P., and Lafon, T.: The SWOT (Surface Water and Ocean Topography) mission: spaceborne radar interferometry for oceanographic and hydrological applications, in: OCEANOBS'09 Conference, 21-25 September 2009, Venice, Italy, 2009.

Garçon, V. C., Oschlies, A., Doney, S. C., McGillicuddy, D., and Waniek, J.: The role of mesoscale variability on plankton dynamics in the North Atlantic, Deep-Sea Res. Pt. II, 48, 2199-2226, https://doi.org/10.1016/S0967-0645(00)00183-1, 2001.

Garric, G., Parent, L., Greiner, E., Drévillon, M., Hamon, M., Lellouche, J., Régnier, C., Desportes, C., Le Galloudec, O., Bricaud, C., Drillet, Y., Hernandez, F., Dubois, C., and Le Traon, P. Y.: Performance and quality assessment of the global ocean eddy-permitting physical reanalysis GLORYS2V4, Operational Oceanography serving Sustainable Marine Development, in: Proceedings of the Eight EuroGOOS International Conference, EuroGOOS, 3-5 October 2017, Bergen, Norway, 516 pp., 2018.

Gaultier, L., Ubelmann, C., and Fu, L.-L.: The Challenge of Using Future SWOT Data for Oceanic Field Reconstruction, J. Atmos.
Ocean. Tech., 33, 119-126, https://doi.org/10.1175/JTECH-D15-0160.1, 2016.

Hallberg, R.: Using a resolution function to regulate parameterizations of oceanic mesoscale eddy effects, Ocean Model., 72, 92103, https://doi.org/10.1016/j.ocemod.2013.08.007, 2013.

Halliwell, G. R., Srinivasan, A., Kourafalou, V., Yang, H., Willey, D., Hénaff, M. L., and Atlas, R.: Rigorous Evaluation of a Fraternal Twin Ocean OSSE System for the Open Gulf of Mexico, J. Atmos. Ocean. Tech., 31, 105-130, https://doi.org/10.1175/JTECH-D-13-00011.1, 2014.

Halliwell, G. R., Mehari, M. F., Hénaff, M. L., Kourafalou, V. H., Androulidakis, I. S., Kang, H. S., and Atlas, R.: North Atlantic Ocean OSSE system: Evaluation of operational ocean observing system components and supplemental seasonal observations for potentially improving tropical cyclone prediction in coupled systems, J. Oper. Oceanogr., 10, 154-175, https://doi.org/10.1080/1755876X.2017.1322770, 2017.

Hénaff, M. L., Mey, P. D., Mourre, B., and Traon, P.-Y. L.: Contribution of a Wide-Swath Altimeter in a Shelf Seas Assimilation System: Impact of the Satellite Roll Errors, J. Atmos. Ocean. Tech., 25, 2133-2144, https://doi.org/10.1175/2008JTECHO576.1, 2008.

Ide, K., Courtier, P., Ghil, M., and Lorenc, A. C.: Unified Notation for Data Assimilation: Operational, Sequential and Variational (gtSpecial IssueltData Assimilation in Meteology and Oceanography: Theory and Practice), J. Meteorol. Soc. Jpn. Ser. II, 75, 181-189, 1997.

Klein, P., Lapeyre, G., and Large, W. G.: Wind ringing of the ocean in presence of mesoscale eddies, Geophys. Res. Lett., 31, 115306, https://doi.org/10.1029/2004GL020274, 2004.

Kourafalou, V. H., Androulidakis, Y. S., Halliwell, G. R., Kang, H., Mehari, M. M., Hénaff, M. L., Atlas, R., and Lumpkin, R.: North Atlantic Ocean OSSE system development: Nature Run evaluation and application to hurricane interaction with the Gulf Stream, Prog. Oceanogr., 148, 1-25, https://doi.org/10.1016/j.pocean.2016.09.001, 2016.

Lellouche, J.-M., Le Galloudec, O., Drévillon, M., Régnier, C., Greiner, E., Garric, G., Ferry, N., Desportes, C., Testut, C.-E., Bricaud, C., Bourdallé-Badie, R., Tranchant, B., Benkiran, M., Drillet, Y., Daudin, A., and De Nicola, C.: Evaluation of global monitoring and forecasting systems at Mercator Océan, Ocean Sci., 9, 57-81, https://doi.org/10.5194/os-9-57-2013, 2013.

Le Traon, P. Y.: From satellite altimetry to Argo and operational oceanography: three revolutions in oceanography, Ocean Sci., 9, 901-915, https://doi.org/10.5194/os-9-901-2013, 2013.

Le Traon, P. Y. and Dibarboure, G.: Mesoscale Mapping Capabilities of Multiple-Satellite Altimeter Missions, J. Atmos. Ocean. Tech., 16, 1208-1223, https://doi.org/10.1175/15200426(1999)016<1208:MMCOMS>2.0.CO;2, 1999.

Le Traon, P. Y. and Morrow, R.: Chapter 3 Ocean Currents and Eddies, in: International Geophysics, Vol. 69, edited by: Fu, L.-L. and Cazenave, A., Academic Press, https://doi.org/10.1016/S0074-6142(01)80148-0, 2001.

Le Traon, P. Y., Antoine, D., Bentamy, A., Bonekamp, H., Breivik, L., Chapron, B., Corlett, G., Dibarboure, G., DiGiacomo, P., Donlon, C., Faugère, Y., Font, J., Girard-Ardhuin, F., Gohin, F., Johannessen, J., Kamachi, M., Lagerloef, G., Lambin, J., Larnicol, G., Borgne, P. L., Leuliette, E., Lindstrom, E., Martin, M., Maturi, E., Miller, L., Mingsen, L., Morrow, R., Reul, N., 
Rio, M., Roquet, H., Santoleri, R., and Wilkin, J.: Use of satellite observations for operational oceanography: recent achievements and future prospects, J. Oper. Oceanogr., 8, s12-s27, https://doi.org/10.1080/1755876X.2015.1022050, 2015.

Le Traon, P. Y., Ali, A., Alvarez Fanjul, E., Aouf, L., Axell, L., Aznar, R., Ballarotta, M., Behrens, A., Mounir, B., Bentamy, A., Bertino, L., Bowyer, P., Brando, V. A., Breivik, L., Buongiorno Nardelli, B., Cailleau, S., Ciliberti, S., Clementi, E., Colella, S., and Zuo, H.: The Copernicus Marine Environmental Monitoring Service: Main Scientific Achievements and Future Prospects, The Copernicus Marine Environmental Monitoring Service: Main Scientific Achievements and Future Prospects, Mercator Ocean J., 56, 2017a.

Le Traon, P. Y., Dibarboure, G., Jacobs, G., Martin, G., Remy, E., and Schiller, A.: Use of satellite altimetry for operational oceanography, in: Satellite Altimetry Over Oceans and Land Surfaces, edited by: Stammer, D. and Cazenave, A., CRC Press, 581-608, 2017b.

Lyard, F., Lefevre, F., Letellier, T., and Francis, O.: Modelling the global ocean tides: modern insights from FES2004, Ocean Dynam., 56, 394-415, https://doi.org/10.1007/s10236-006-0086-x, 2006.

Madec, G.: NEMO ocean engine, http://www.nemo-ocean.eu/ About-NEMO/Reference-manuals/NEMO_book_3.6_STABLE (last access: March 2018), 2016.

Maraldi, C., Chanut, J., Levier, B., Ayoub, N., De Mey, P., Reffray, G., Lyard, F., Cailleau, S., Drévillon, M., Fanjul, E. A., Sotillo, M. G., Marsaleix, P., and Team, M.: NEMO on the shelf: assessment of the Iberia-Biscay-Ireland configuration, Ocean Sci., 9, 745-771, https://doi.org/10.5194/os-9-745-2013, 2013.

Morrow, R. and Le Traon, P.-Y.: Recent advances in observing mesoscale ocean dynamics with satellite altimetry, Adv. Space Res., 50, 1062-1076, https://doi.org/10.1016/j.asr.2011.09.033, 2012

Oddo, P., Bonaduce, A., Pinardi, N., and Guarnieri, A.: Sensitivity of the Mediterranean sea level to atmospheric pressure and free surface elevation numerical formulation in NEMO, Geosci. Model Dev., 7, 3001-3015, https://doi.org/10.5194/gmd-7-30012014, 2014.

Oke, P. R., Larnicol, G., Fujii, Y., Smith, G., Lea, D., Guinehut, S., Remy, E., Balmaseda, M. A., Rykova, T., Surcel-Colan, D., Martin, M., Sellar, A., Mulet, S., and Turpin, V.: Assessing the impact of observations on ocean forecasts and reanalyses: Part 1, Global studies, J. Oper. Oceanogr., 8, s49-s62, https://doi.org/10.1080/1755876X.2015.1022067, 2015a.

Oke, P. R., Larnicol, G., Jones, E., Kourafalou, V., Sperrevik, A., Carse, F., Tanajura, C., Mourre, B., Tonani, M., Brassington, G. B., Le Henaff, M., Halliwell Jr., G. R., Atlas, R., Moore, A., Edwards, C., Martin, M., Sellar, A., Alvarez, A., Mey, P. D., and Iskandarani, M.: Assessing the impact of observations on ocean forecasts and reanalyses: Part 2, Regional applications, J. Oper. Oceanogr., 8, s63-s79, https://doi.org/10.1080/1755876X.2015.1022080, 2015b.

Oke, P. R. and Schiller, A.: Impact of Argo, SST, and altimeter data on an eddy-resolving ocean reanalysis, Geophys. Res. Lett., 34, 119601, https://doi.org/10.1029/2007GL031549, 2007.

Oke, P. R., Brassington, G. B., Griffin, D. A., and Schiller, A.: The Bluelink ocean data assimila- tion system (BODAS), Ocean Model., 21, 46-70, https://doi.org/10.1016/j.ocemod.2007.11.002, 2008.

Pascual, A., Faugère, Y., Larnicol, G., and Le Traon, P.-Y.: Improved description of the ocean mesoscale variability by combining four satellite altimeters, Geophys. Res. Lett., 33, 102611, https://doi.org/10.1029/2005GL024633, 2006.

Ponte, A. L. and Klein, P.: Reconstruction of the upper ocean 3D dynamics from high-resolution sea surface height, Ocean Dynam., 63, 777-791, https://doi.org/10.1007/s10236-013-0611-7, 2013.

Pujol, M.-I., Dibarboure, G., Traon, P.-Y. L., and Klein, P.: Using High-Resolution Altimetry to Observe Mesoscale Signals, J. Atmos. Ocean. Tech., 29, 1409-1416, https://doi.org/10.1175/JTECH-D-12-00032.1, 2012.

Roblou, L., Lamouroux, J., Bouffard, J., Lyard, F., Le Hénaff, M., Lombard, A., Marsaleix, P., De Mey, P., and Birol, F.: Postprocessing Altimeter Data Towards Coastal Applications and Integration into Coastal Models, Springer, Berlin, Heidelberg, 217 246, https://doi.org/10.1007/978-3-642-12796-0_9, 2011.

Ruggiero, G. A., Cosme, E., Brankart, J.-M., Sommer, J. L., and Ubelmann, C.: An efficient way to account for observation error correlations in the assimilation of data from the future SWOT High-Resolution altimeter mission, J. Atmos. Ocean. Tech., 33, 2755-2768, https://doi.org/10.1175/JTECH-D-16-0048.1, 2016.

Schiller, A., Bell, M., Brassington, G., Brasseur, P., Barciela, R., Mey, P. D., Dombrowsky, E., Gehlen, M., Hernandez, F., Kourafalou, V., Larnicol, G., Traon, P.-Y. L., Martin, M., Oke, P., Smith, G. C., Smith, N., Tolman, H., and Wilmer-Becker, K.: Synthesis of new scientific challenges for GODAE OceanView, J. Oper. Oceanogr., 8, s259-s271, https://doi.org/10.1080/1755876X.2015.1049901, 2015.

Sotillo, M. G., Cailleau, S., Lorente, P., Levier, B., Aznar, R., Reffray, G., Amo-Baladrón, A., Chanut, J., Benkiran, M., and Alvarez-Fanjul, E.: The MyOcean IBI Ocean Forecast and Reanalysis Systems: operational products and roadmap to the future Copernicus Service, J. Oper. Oceanogr., 8, 63-79, https://doi.org/10.1080/1755876X.2015.1014663, 2015.

Thomson, R. E. and Emery, W. J.: Chapter 5 - Time Series Analysis Methods, in: Data Analysis Methods in Physical Oceanography, 3rd Edn., edited by: Thomson, R. E. and Emery, W. J., Elsevier, Boston, 425-591, https://doi.org/10.1016/B978-0-12387782-6.00005-3, 2014.

Ubelmann, C., Klein, P., and Fu, L.-L.: Dynamic Interpolation of Sea Surface Height and Potential Applications for Future HighResolution Altimetry Mapping, J. Atmos. Ocean. Tech., 32, 177184, https://doi.org/10.1175/JTECH-D-14-00152.1, 2015.

Ubelmann, C., Dibarboure, G., and Dubois, P.: A cross-spectral approach to measure the error budget of the SWOT altimetry mission over the Ocean, J. Atmos. Ocean. Tech., 35, 845-857, https://doi.org/10.1175/JTECH-D-17-0061.1, 2017.

Verrier, S., Le Traon, P.-Y., and Remy, E.: Assessing the impact of multiple altimeter missions and Argo in a global eddypermitting data assimilation system, Ocean Sci., 13, 1077-1092, https://doi.org/10.5194/os-13-1077-2017, 2017.

Wunsch, C. and Stammer, D.: Atmospheric loading and the oceanic "inverted barometer" effect, Rev. Geophys., 35, 79-107, https://doi.org/10.1029/96RG03037, 1997. 